\title{
The subject advantage in relative clauses: A review
}

\section{Glossa}

a journal of general linguistics

\section{ELAINE LAU (1)}

\section{NOZOMI TANAKA (D)}

*Author affiliations can be found in the back matter of this article

\section{Abstract}

The question of whether there exists a universal subject preference in relativization has stimulated research in a wide range of languages and across different domains, yielding an extensive body of literature in relative clause acquisition and processing. In this article, we aim at consolidating the efforts of existing research in order to inform further exploration of the universality of the subject preference with a comprehensive analysis of relevant work (including journal articles on empirical studies, dissertations, and conference proceedings). We present an overview of the proposals regarding the source(s) of the subject-object asymmetry from a crosslinguistic perspective and discuss commonly used methodologies in this research area, and we survey the research on relative clause processing and acquisition of different linguistic communities, including native speakers, second language learners, clinical populations, and heritage speakers.

\section{CORRESPONDING AUTHOR:}

\section{Nozomi Tanaka}

Department of East Asian Languages and Cultures, Indiana University, IN, US tanakan@iu.edu

\section{KEYWORDS:}

relative clause; language processing; language acquisition; second language acquisition; heritage language; language disorder

TO CITE THIS ARTICLE: Lau, Elaine and Nozomi Tanaka. 2021. The subject advantage in relative clauses: A review. Glossa: a journal of general linguistics 6(1): 34. 1-34. DOI: https://doi. org/10.5334/gjgl.1343 


\section{Introduction}

While relative clauses (RCs) tend to be acquired late and to cause processing difficulties, some types of RCs are easier to acquire and process than others. For instance, there is a wellresearched subject-object asymmetry in relativization, as in the English examples in (1) and (2). Subject RC (SRC): The boy [ that __ chased the girl] Direct object RC (ORC): The boy [ that the girl chased __]

Findings from Indo-European languages generally support a "universal" subject advantage: adults process SRCs more quickly and accurately than ORCs; children understand and produce SRCs earlier than ORCs. Research on typologically distinct languages and with groups other than monolingual native speakers, however, casts doubt on the universality of these patterns.

This overview paper critically reviews the state-of-the-art literature on RC processing and acquisition in order to evaluate proposals regarding the source of the subject-object asymmetry as well as the methodologies devised to investigate it. ${ }^{1}$ We draw on findings from a wide range of languages. Virtually all languages have RCs; hence, understanding how they are processed and acquired across languages illuminates general cognitive principles of human language processing. We point out a general convergence toward a "true" subject preference, but also identify contradictions and remaining questions to encourage a multifactorial view. Although we focus on research on typical monolingual native speaker populations, we also touch on the theoretical and practical implications of research on second and heritage language speakers and clinical populations.

Section 2 introduces the subject-object asymmetry, and Section 3 reviews proposals on its sources. Section 4 addresses whether these proposals are borne out by cross-linguistic work. Section 5 describes common methodological approaches to the phenomenon. Sections 6 and 7 briefly review research on clinical and multilingual populations, respectively. Section 8 concludes.

\section{The phenomenon}

In Keenan \& Comrie's (1977) noun phrase accessibility hierarchy (NPAH), based on typological observations from approximately 50 languages, accessibility refers to an NP's relative availability to grammatical processes:

$$
\begin{aligned}
& \text { Subject }>\text { Direct Object }>\text { Indirect Object }>\text { Oblique }>\text { Genitive }>\text { Object of } \\
& \text { Comparison }
\end{aligned}
$$

According to the NPAH, if a language allows relativization (and other extractions) of one NP type, it should allow the relativization of all NPs to its left in the hierarchy. If a language can relativize direct objects, for instance, it should be able to relativize subjects. However, the same language may or may not allow relativization of indirect objects or any other NP type to its right.

The NPAH generalizes a typological implication but lacks explanation (a deliberate choice, according to Comrie 2007); subsequent works explore its psychological reality. If there is "progressively greater difficulty in processing RCs as the clause's place in the hierarchy decreases," then the NPAH can "serve as a predictor of psychological complexity" (Keenan \& Hawkins 1987: 61). The notion of accessibility therefore extends to ease of retrieval/activation of RC structures from memory, reflected in relative ease of processing and/or acquisition. The difficulty of less accessible RC types can manifest in the following forms:

\section{COMPREHENSION}

- lower accuracy

- longer processing time

- more working memory burden

\footnotetext{
1 In order to make the overview as comprehensible as possible, we included dissertations, journal articles, and conference proceedings, and, if they were the only source on a language, conference presentations, master's theses, and working papers. Due to space limitations, the reference list only contains studies cited in the text, but summaries of 323 relevant studies can be found in the Supplementary Files.
} 


\section{PRODUCTION}

- slower responses

- more errors

- more omissions/substitutions

\section{CHILD LANGUAGE ACQUISITION/SECOND LANGUAGE LEARNING}

- later emersion and acquisition

- more avoidance

Early research on child and second language acquisition (e.g. Brown 1971; Hatch 1971; Legum 1975; Keenan \& Hawkins 1987) showed an apparent correlation between order of RC mastery and the NPAH. Later work on adult language processing found a similar hierarchy of preferences. As most studies focus on the contrast between SRCs and ORCs, the terms subjectobject asymmetry and subject advantage/preference are commonly used. Although the subject advantage can apply to both intransitive and transitive SRCs, more studies focus on transitive structures, as intransitive SRCs do not have an ORC counterpart for comparison. Some studies also include other positions on the NPAH (e.g. Kim \& O'Grady 2016; Lin 2018). This review attempts to cover relevant work to understand both the basis of the subject advantage and whether it is truly universal.

The next section reviews the most prominent proposals regarding the source of the subjectobject asymmetry.

\section{Source(s) of the subject-object asymmetry}

This section categorizes proposals regarding the source of the subject-object asymmetry as follows: resource-based effects (3.1), structural effects (3.2), canonicity effects (3.3), distribution-based effects (3.4), and prominence effects (3.5). These proposals are different in terms of their scope. Some apply only to comprehension or production, and some only to processing or acquisition; others are relevant to all of these domains. They also differ in rigor, with some proposals having more predictive power than others. The intention of this paper, however, is to offer a comprehensive review spanning the different domains in the hope of providing a bigger picture and benefiting a wider audience.

\subsection{Resource-based effects}

Processing RCs requires resolving a filler-gap dependency; that is, integrating the information of the RC's head noun (filler) and its gap to understand how they are related in order to interpret the RC. The assumption is that the language processor needs to hold the information of one end of the dependency (either the gap or the head noun, depending on RC head direction; Section 4.1) in working memory until encountering the other end of the dependency, when resolution becomes possible.

In this view, the subject-object asymmetry is caused by the working memory cost of processing the dependency, which can be captured as the linear distance between the head and the gap (Wanner \& Maratsos 1978; Tarallo \& Myhill 1983; King \& Just 1991). In English, the distance (number of intervening words) between the head and its gap is longer in ORCs (5) than SRCs (4). Hence, processing ORCs creates a greater burden on working memory, because the filler must be retained for a longer distance before the dependency is resolved.

$$
\text { the boy [that_saw the girl] }
$$

SRC

$$
\text { the boy [that the girl saw }
$$

ORC 
In Gibson's (1998; 2000) dependency locality theory, processing cost is calculated as number of new discourse referents (e.g. NPs, tensed verbs) rather than intervening words. New discourse referents require additional processing effort to integrate and store while structure is built for them (Gibson 1998: 12). In the ORC in (7), two discourse referents (i.e. co-argument and verb) intervene between the filler and the gap; in the SRC in (6), no discourse referent intervenes. This difference is predicted to make ORCs more difficult than SRCs to process.

$$
\text { the boy [ that } \_ \text {saw the girl ] } \quad \text { SRC }=0 \text { referent }
$$

$$
\begin{gathered}
\text { the boy [ that the girl saw } \\
\text { REL NP }] \quad \text { ORC }=2 \text { referents }
\end{gathered}
$$

Warren \& Gibson (2002) demonstrated that processing costs are also dependent on the discourse accessibility of a referent, meaning the degree to which its antecedent is accessible. For example, based on givenness, pronouns are more accessible than proper names in discourse (Gundel et al. 1993); thus, RCs with an intervening pronominal element can be read faster than RCs with intervening proper names.

Resource-based accounts center on the linear distance of the filler-gap dependency, which depends on RC structure. The original hypothesis was based on European languages, which mostly have SVO word order and postnominal RCs, and which mostly show a subject advantage. For languages with different word orders and different RC structural configurations, however, resource-based effects may have different outcomes (Section 4.1).

\subsection{Structural effects}

The hierarchical structure of languages may also account for the subject-object asymmetry. Direct objects occur lower and more deeply embedded in syntactic structure than subjects. If more deeply embedded constituents require more computational effort to access than less deeply embedded constituents, then direct objects will be less accessible (hence more difficult to process) than subjects. The structural effects account implies the universality of the subject advantage, because subjects are presumably higher than direct objects in syntactic structure in all languages (see, however, Section 4.3 on ergative languages). While this account can also be considered "resource-based" as it centers on processing ease, we discuss it separately due to the focus on structural rather than linear representation.

Frazier's (1987) study exploited the surface ambiguity between SRCs and ORCs in Dutch and German. Embedded clauses in these V2 languages have SOV word order; verb position does not differentiate SRCs and ORCs. In addition, when subject and object have the same person and number, subject-verb agreement does not help distinguish RC types. Hence, the RC in (8) can be interpreted as an SRC (a) or an ORC (b) (Frazier 1987: 545, ex. 26).

Ik schreef aan de vriend [die mijn tante heeft bezocht].

I wrote to the friend who my aunt have-SG visited)

a. SRC interpretation:

Ik schreef aan de vriend [die _ mijn tante heft bezocht].

I wrote to the friend who my aunt have-SG visited

'I wrote to the friend who has visited my aunt.'

b. ORC interpretation:

Ik schreef aan de vriend [die mijn tante _ heft bezocht].

I wrote to the friend who my aunt have-SG visited

'I wrote to the friend whom my aunt has visited.'

Native Dutch- and German-speaking adults interpret such ambiguous RCs as SRCs more frequently than ORCs (Frazier 1987; Schriefers et al. 1995). According to Frazier's (1987) active-filler hypothesis, the language processor tends to resolve a dependency at the earliest opportunity upon identifying a filler, thus initially assigning an SRC interpretation to all RC structures because subject gaps appear sooner than any other position. Therefore, ORCs are more difficult to process both because the RC head has to be held in working memory longer, and because the initial misanalysis as an SRC must be revised. 
In an alternative structural account, an RC's difficulty depends on the embeddedness/depth of the gap in terms of the number of syntactic nodes crossed by the dependency (Collins 1994; O'Grady 1997: 135-136; Hawkins 1999; 2004). Examples (9) and (10) present a schematic sketch of the structure of SRCs and ORCs in English, following Lin (2015). While there have been different proposals as to how to measure the structural distance, one way is to count the intervening XP nodes between the head and gap (Collins 1994; O'Grady 1997: 135-136), of which the SRC in (9) has two (CP, IP) and the ORC in (10) has three (CP, IP, VP). Therefore, the object gap is more deeply embedded in the syntactic structure, and the structural distance between the head and the gap is greater in ORCs than SRCs.

(9)

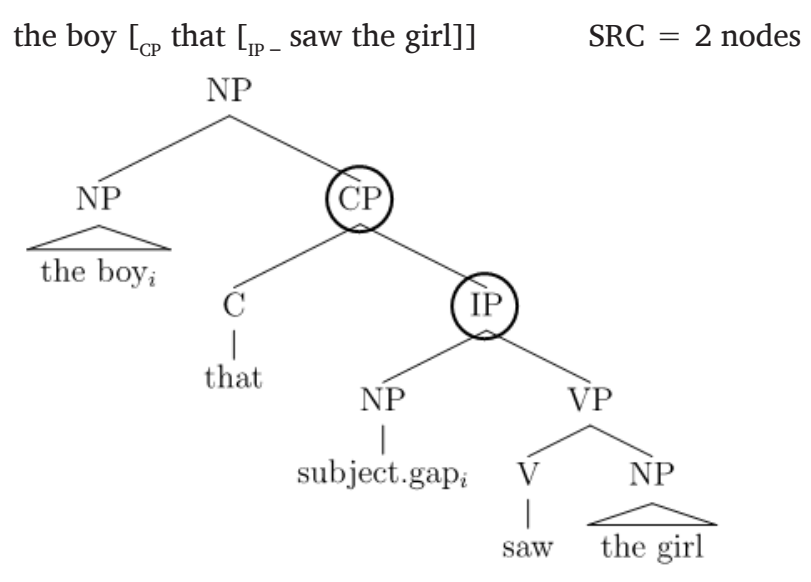

(10)

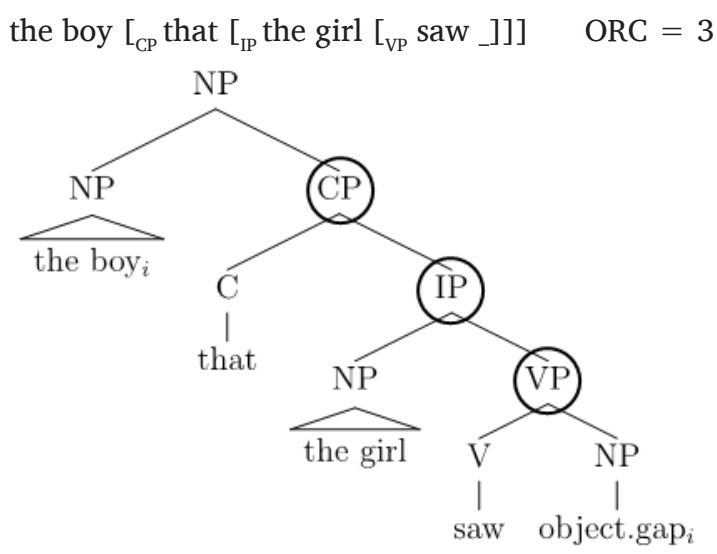

Another type of structural effect is an intervention effect (Friedmann et al. 2009), built on the idea of relativized minimality: a local relation between a target and its trace will fail if there is a hierarchical intervention by an element whose featural specifications fully match those of the target (Rizzi 1990). In the case of RCs, nothing intervenes between target (head) and trace (gap/resumption) in SRCs, but in ORCs, the subject hierarchically intervenes and shares some features with the target. The intervention effect decreases if the intervener and the target are dissimilar, but there is a developmental difference (Friedmann et al. 2009). A partial match of featural specifications is generally acceptable to adults (i.e. the local relation between target and trace holds despite the hierarchical intervention), but intervention effects may still manifest as complexity effects such as performance delays. Children operate on a stricter principle: even a partial match of features between the intervening subject and the target causes comprehension and production breakdown. Works on intervention effects have explored features such as gender, lexical restriction, and number (e.g. Belletti et al. 2012; Friedmann et al. 2009).

\subsection{Canonicity effects}

The language processor is assumed to employ a canonical sentence schema to interpret sentences (Swinney \& Love 1998; Sekerina 2003). Thus, structures in a language's canonical word order should be easier to process and acquire. The arguments' thematic and grammatical roles in a sentence are also expected to follow the relative order in a prototypical transitive clause, as shown by a tendency to interpret a first NP as both subject and agent. 
Canonicity effects (or thematic ordering effects) appear to be important in acquisition (Bever 1970; Slobin \& Bever 1982; MacWhinney et al. 1984). Bever's (1970) child participants performed well with SRCs but randomly with ORCs; Bever argued that the children were using a canonical NVN-schema to interpret the RCs, which succeeded with SRCs due to their NVN word order (11), but failed with ORCs due to their NNV word order.

N
the boy [_t that saw the girl]
N
the girl [that the boy saw ]

Diessel \& Tomasello (2005; see also Diessel 2009) also tested children's comprehension and production of RCs, finding that ORCs were more difficult for children to imitate than SRCs. They explained the finding as a canonicity effect: both intransitive (SV) and transitive (SVO) SRCs (13)-(14) follow the canonical word order, whereas the OSV word order of ORCs (15) is non-canonical.

$$
\begin{aligned}
& \text { S } \\
& \text { the boy [that_ ran] } \\
& \text { S } \\
& \text { the boy [ that_saw the girl] } \\
& \text { O } \\
& \text { the girl [that the boy saw ] }
\end{aligned}
$$

Additional evidence for canonicity effects comes from the reversal error frequently observed in children's comprehension of ORCs (Diessel \& Tomasello 2005). If children see a pair of reversible pictures (e.g. a girl chasing a boy vs. a boy chasing a girl) and must select one that matches the RC they hear (see Section 5), they often select the distractor picture (the one depicting the characters in the wrong thematic roles) in ORC conditions. This suggests that children choose characters' thematic roles according to the characters' order of appearance in the sentence, resulting in a mis-assignment of the thematic roles in ORCs.

It is not clear, however, how to quantify such canonicity effects. For example, what prediction can be made when two non-canonical word orders are compared? We explore this matter further in Section 4's discussion of languages with different word orders and RC configurations.

\subsection{Distribution-based effects}

What is frequent in natural (or child-directed) speech is, research suggests, acquired earlier by children and more easily comprehended and produced by adults (Ambridge et al. 2015). A distribution-based approach considers how different distributional properties of RC types influence processing and acquisition. The animacy of the RC head noun, for example, is a strong indicator of RC type: in adult production, SRCs are more likely to have an animate head, and ORCs an inanimate head (Fox \& Thompson 1990; Roland et al. 2007). Sentence continuation research also shows the effects of head animacy: native English speakers tend to complete a given RC with an animate head as an SRC, and one with an inanimate head as an ORC (Mak et al. 2002; Gennari \& MacDonald 2008). Child language also shows the association of SRCs with animate heads and ORCs with inanimate heads (e.g. English: Diessel 2004; Kidd et al. 2007; German: Kidd et al. 2007). Table 1 summarizes corpus findings on the distribution of English SRCs and ORCs with animate and inanimate head nouns.

Studies on adult processing (Mak et al. 2002; 2006; Traxler et al. 2002; 2005) and child acquisition (Kidd et al. 2007) show that the difficulty associated with ORCs varies with the animacy of the head and the co-argument, and that the SRC advantage can be neutralized by manipulating the animacy configuration. ORCs are easier to process when they have animate subjects and inanimate objects (16), and harder when the arguments' animacy is reversed (17). Relative ease of processing may emerge when the animacy configuration matches the processor's expectations based on prototypical thematic/grammatical roles of the arguments in a transitive clause, while relative difficulty may emerge when the animacy configuration is reversed (17) because the same expectations lead to initial misanalysis. (16-17) are adapted from Mak et al. (2002). 


\begin{tabular}{llll}
\hline & SRC & ORC & Sources \\
\hline \multirow{2}{*}{ Adult } & & & \\
\hline & $75 \%$ & - & Brown Corpus (Roland et al. 2007) \\
\cline { 2 - 4 } & $91 \%$ & - & Switchboard Corpus (Roland et al. 2007) \\
\cline { 2 - 4 } & $85 \%$ & $15 \%$ & Sentence completion data (Gennari \& MacDonald 2008) \\
\cline { 2 - 4 } Inanimate & $34 \%$ & $56 \%$ & Spontaneous speech data (Fox \& Thompson 1990) \\
\cline { 2 - 4 } & $47 \%$ & - & Brown Corpus (Roland et al. 2007) \\
\cline { 2 - 4 } Child & $65 \%$ & - & Switchboard Corpus (Roland et al. 2007) \\
\hline Animate & $47.8 \%$ & $30.8 \%$ & Brown Corpus (Diessel 2004) \\
\cline { 2 - 4 } & & $10.5 \%$ & Brown/Suppes/Bloom Corpus (Kidd et al. 2007) \\
\hline Inanimate & $32.2 \%$ & $40.2 \%$ & Brown Corpus (Diessel 2004) \\
\cline { 2 - 4 } & & $75 \%$ & Brown/Suppes/Bloom Corpus (Kidd et al. 2007) \\
\hline
\end{tabular}

(16) Animate subject-Inanimate object

a. SRC: the hiker [that _ rolled away the rock]

b. ORC: the rock [that the hiker rolled away _]

Inanimate subject-Animate object

a. SRC: the rock [that _ crushed the hiker]

b. ORC: the hiker [that the rock crushed_]

Pronominality is also crucial in RC processing: when an ORC's subject is a personal pronoun (18), the subject-object asymmetry may be neutralized or reversed (Gordon et al. 2001; Reali \& Christiansen 2007).

(18) The consultant [ that you called ]

Reali \& Christiansen (2007) attributed the ease of processing pronominal ORCs to high frequency in daily use. Discourse factors tend to lead to ORCs having inanimate heads and pronominal subjects; their frequency increases their accessibility, which guides the processor's expectations.

\subsection{Prominence effects}

From a semantic rather than a syntactic perspective, the prominence of subjects in discourse may make them more accessible for RC processing (Mak et al. 2006; O'Grady 2011; Lin 2018). Lin (2018: 716) proposed that the subject position, as the default for topic/case, is more prominent and receives more attention. Assuming that head nouns are preferably associated with arguments of greater discourse prominence, SRCs are easier to process because they provide information about the prominent entity in the discourse, matching prominence expectations.

Building on Schachter's (1977) idea of foregrounding, Kuno's (1976) idea of topicality (see also Givón 1983), and MacWhinney's idea of perspective (MacWhinney 1977; 2005; MacWhinney \& Pléh 1988), O'Grady (2011: 21) formulated the notion of a "prominence factor":

(19) The ease with which the processor establishes an aboutness relationship with a nominal is proportional to the prominence of that nominal's referent within the RC. (A referent functioning as subject within the RC is most prominent, a referent functioning as direct object is next most prominent, and so on.)

That is, when the head noun of an RC refers to a more prominent entity, the RC is easier to process.

Mak et al. (2006; 2008) similarly attributed prominence to argument topichood: the subject is by default the sentential/clausal topic (Lambrecht 1994: 134; Aissen 1999), and the head noun is the topic of the RC (Kuno 1976; Van Valin \& Wilkins 1996). Another dimension of topichood comes from discourse: the topic is the entity that the event is about (a further dimension is being the agent at the thematic level; O'Grady 2011). In comprehension, readers have a 
tendency to align topics at different levels with the same entity, choosing the discourse topic as the RC subject, expecting it to be the agent, and aligning it with the head noun.

In this view, topicworthiness determines which entity in an event is the head noun/subject of the RC. Topicworthiness is based on various factors including givenness (Gordon et al. 2001; Mak et al. 2008) and animacy (Van Valin \& Wilkins 1996). Personal pronouns, having greater givenness, are more topicworthy than full NPs; animate entities are more topicworthy than inanimate entities. Hence, the most topicworthy entity is assumed to be the discourse topic, the agent of the event, the RC subject, and the head noun.

The same tendencies are observed in production (Montag \& MacDonald 2009; Gennari et al. 2012). Given an animate theme head, English-speaking adults produce syntactically more complex passive SRCs (20) more often than active ORCs (21). Examples (20-21) are from Montag \& MacDonald (2009: 2594).

$$
\begin{array}{ll}
\text { The baby (that/who is) being held by the woman. } & \text { Passive SRC } \\
\text { The baby (that/who) the woman is holding. } & \text { ORC }
\end{array}
$$

Prominence may also ameliorate ORC difficulty (Section 3.4): ORCs with a pronominal subject or an expectation-matching animacy configuration (i.e. animate subject-inanimate object) are easier to process because the more topicworthy entity takes the subject (topic) position, matching the topichood expectation.

\subsection{Interim summary}

This section introduced proposals for the source(s) of the subject-object asymmetry in IndoEuropean languages, which generally predict the subject advantage. Next, we review RC studies in other languages, including some with prenominal RCs and ergative-absolutive languages, showing that the same proposals can predict varied outcomes, and that the subject advantage can be modulated by a variety of factors.

\section{Cross-linguistic considerations}

Investigations in non-Indo-European language families with typological variations in RC construction offer an opportunity to tease apart the confounding and complex effects of morphosyntactic and semantic properties on RC processing.

This section discusses typological variations in word order, headedness, resumption, and morphosyntactic alignment. It illustrates how specific variations might affect RC processing/ acquisition difficulty, which might in turn affect SRC/ORC preferences.

\subsection{Word order and headedness}

Cross-linguistic variation in word order and in RC head directionality affects the constituent order in RC constructions. First, word order determines the location of the gap and its distance from the head noun, which affects the number of intervening elements in RC dependencies. For example, English (22) is an SVO language and Persian (23) is an SOV language. Both have postnominal RCs, but their different constituent orders result in different dependency lengths.

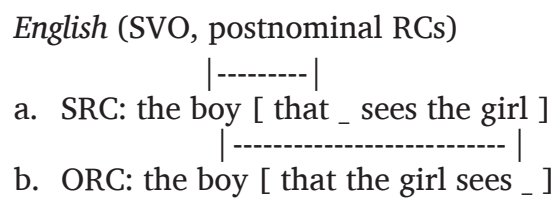


Second, RCs can be prenominal or postnominal, which determines whether RCs come before or after the head noun. The accounts based on linear distance or linear order of the dependency-resource-based effects and canonicity effects-generate opposite predictions on RC difficulty depending on head directionality. For example, Mandarin RCs are prenominal (24). Consequently, the dependency is shorter for ORCs than SRCs. ORCs also have fewer intervening elements in the dependency. According to resource-based accounts, the RC type with a shorter dependency should incur a lower processing cost (and be easier to acquire). Hence, Mandarin would be predicted to show an object advantage, rather than the subject advantage of languages with postnominal RCs like English.

$$
\begin{aligned}
& \text { Mandarin (SVO, prenominal RCs) } \\
& \text { a. SRC: [_ kanjian nuhai] de nanhai } \\
& \text { see girl REL boy } \\
& \text { 'the boy that sees the girl' } \\
& \text { b. ORC: [nuhai kanjian_] de nanhai } \\
& \text { girl see the boy that the girl sees' }
\end{aligned}
$$

The interaction between a language's word order and its RC configuration allows us to examine which factors might have universal effects on RC processing and acquisition. For example, English and Mandarin are both SVO languages, but differ in RC placement. Meanwhile, Mandarin, Japanese (25), and Korean (26) all have prenominal RCs, but Japanese and Korean are SOV languages.

$$
\begin{aligned}
& \text { Japanese (SOV, prenominal RCs) } \\
& \text { a. SRC: [_ inu-o mi-ta ] kodomo } \\
& \text { dog-ACC see-PST child } \\
& \text { 'the child that saw the dog' }
\end{aligned}
$$

$$
\begin{aligned}
& \text { Korean (SOV, prenominal RCs) } \\
& \text { a. SRC: [ namca-lul po-nun] yeca } \\
& \text { man-ACC see-RC.PRS woman } \\
& \text { 'the woman that sees the man' } \\
& \text { b. ORC: [ namca-ka - po-nun] yeca } \\
& \text { man-NOM see-RC.PRS woman } \\
& \text { 'the woman that the man sees' }
\end{aligned}
$$

A resource-based effects account predicts a subject advantage for English and an object advantage for Mandarin due to the differences in the length of the dependency between SRCs and ORCs. ORCs should also be preferred in Japanese and Korean, as their prenominal RC configuration (opposite constituent order from English) creates a longer dependency in SRCs.

However, if memory effects are associated with the cost of integrating information, Japanese and Korean may not have a subject-object asymmetry (Gibson \& Wu 2013). This is because the verb (where the NP information is integrated) is right next to the head noun in both types of RCs.

A canonicity effects account, which claims that ease of processing stems from expectations for upcoming clauses based on canonical word order, also favors ORCs over SRCs in Mandarin, where SRCs have a non-canonical word order, while ORCs follow the canonical word order. In contrast, in Japanese and Korean, both SOV languages, neither SRCs nor ORCs follow the canonical word order; thus, no subject advantage would be predicted (Diessel 2007).

Although the alignment of constituent order with canonical word order gives ORCs a processing advantage in Mandarin, it can also cause interference in comprehension. The matching constituent order results in surface identity between ORCs and transitive clauses, creating temporary main-clause ambiguity before the relativizer or head appears. This can cause gardenpath effects (Lin \& Bever 2011), requiring reanalysis and higher processing costs. 
In contrast, accounts based on structural complexity and subject prominence are unaffected by variations in RC configuration and word order. Universal syntactic and semantic properties of subject arguments (e.g. higher position in syntactic structure; topic prominence in discourse) should support a subject preference regardless of a language's RC configuration and word order. Figures 1 and 2 summarize findings on the RC preferences of nominative-accusative languages from child and adult studies respectively. ${ }^{2}$

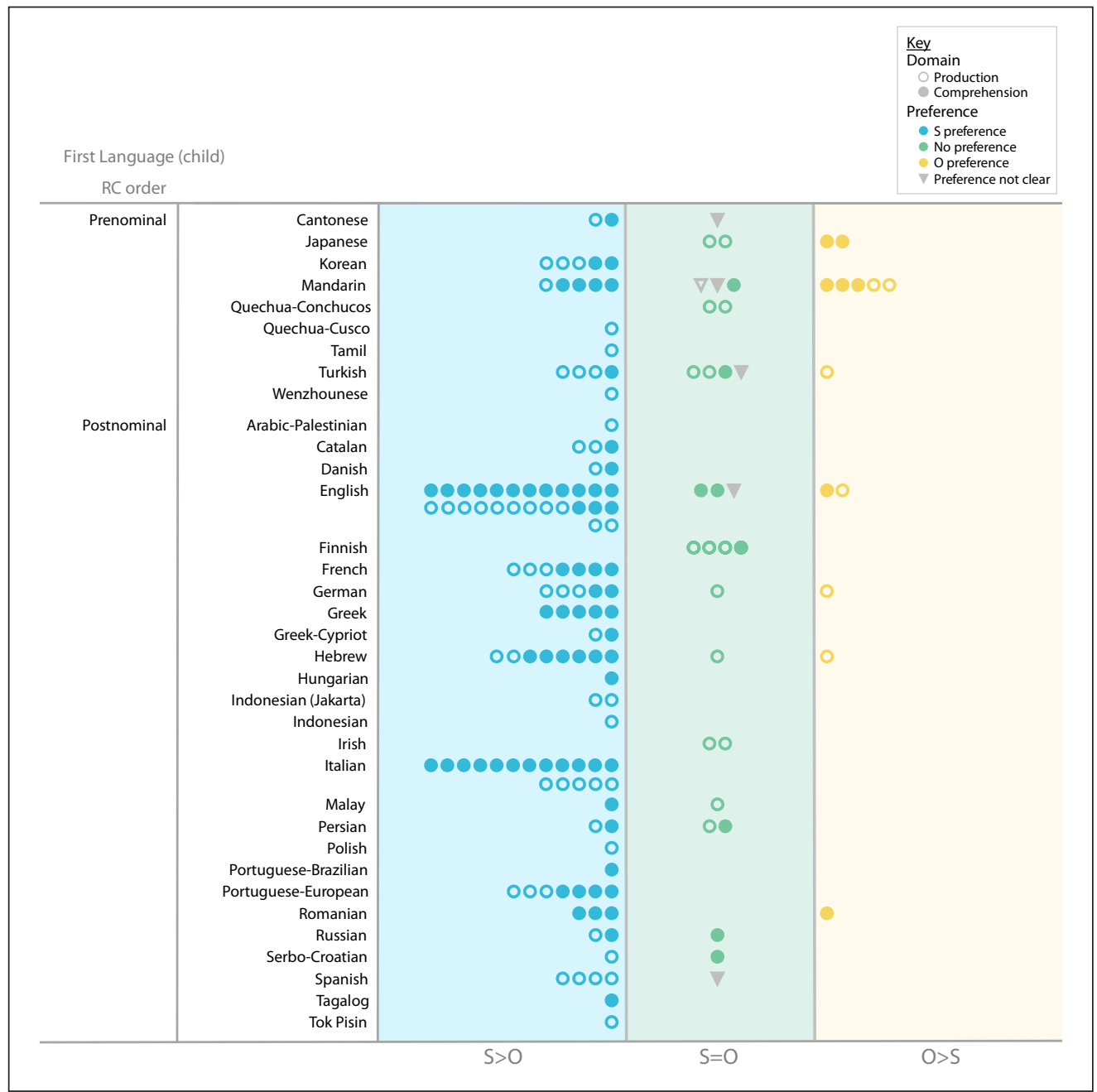

As the figures show, a large majority of languages with postnominal RCs show a subject preference. Although some languages show no preference, an object preference is very rare.

Languages with prenominal RCs are less consistent, except for Korean, which shows a consistent subject advantage. For Cantonese, Japanese, Mandarin, and Turkish, on which a number of studies exist, there is a tug-of-war: some studies report a subject advantage, some report no preference, and others report an object advantage. (On Mandarin RCs, see Section 5.2.)

Importantly, however, production studies are subject to less variability. This is likely because production research is less affected than comprehension research by confounds such as the garden-path effects mentioned above. When garden-path effects are eliminated (Lin \& Bever 2011; Jäger et al. 2015), these languages also show a subject advantage.

Some languages allow both prenominal and postnominal RCs, presenting a critical test case for the effect of headedness. While studies on these languages show the interpretation of an RC is affected by its placement, the subject advantage persists, albeit weakened, for prenominal RCs. Wagers et al. (2018) found that Chamorro shows a subject preference in both prenominal and postnominal RCs when the interpretation is unambiguous. While interpretations of an ambiguous RC show a subject preference for postnominal RCs and an object preference for prenominal RCs, Wagers et al. found that the subject interpretation becomes available to speakers sooner, even if
Figure 1 Summary of RC studies on child acquisition in nominative-accusative languages. Each symbol represents a relevant experiment in a study. 


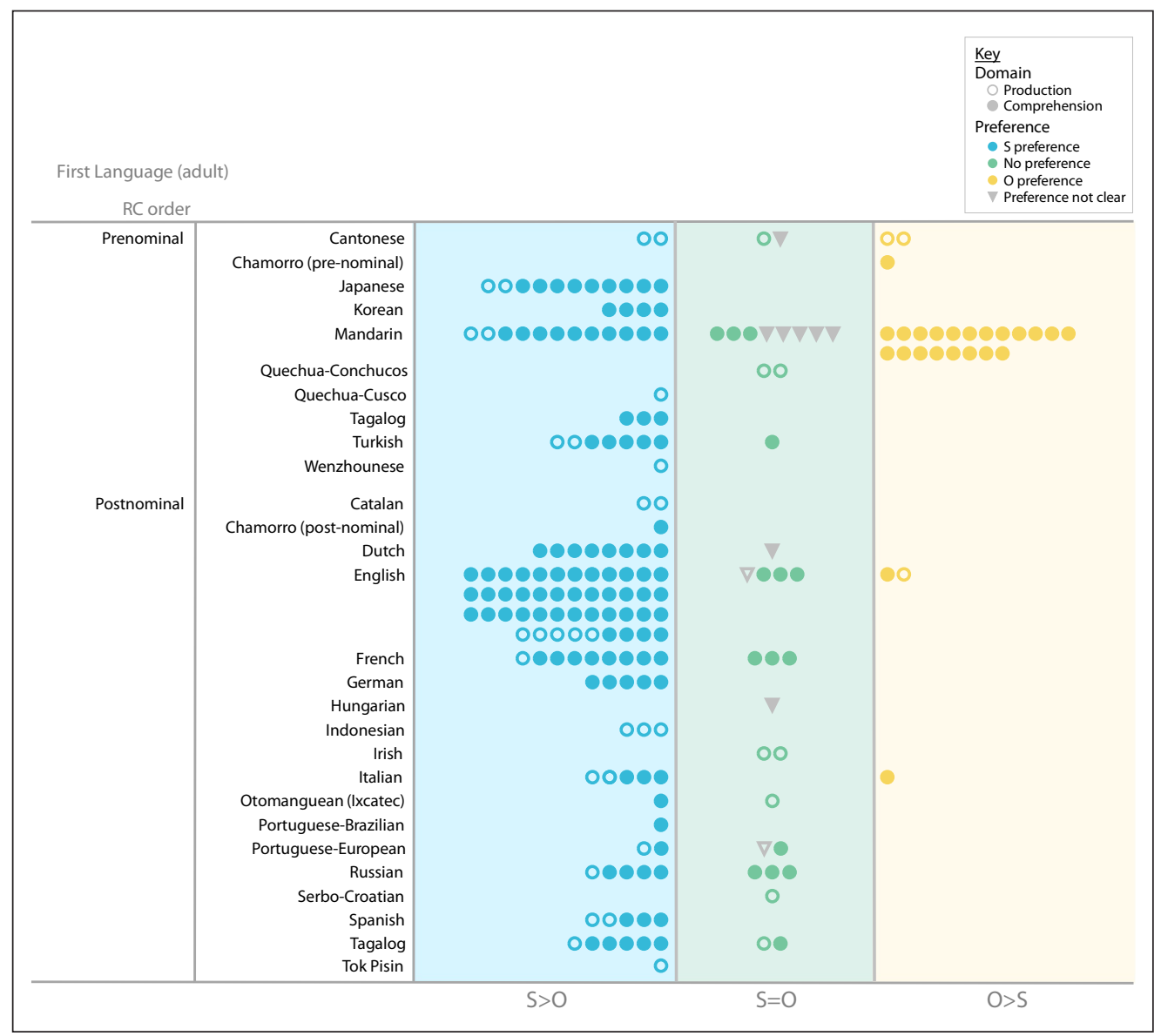

it does not manifest in their interpretation. In Tagalog, another Austronesian language, Tanaka et al. (2019) and Pizarro-Guevara (2020) found an SRC advantage with postnominal RCs. Pizarro-Guevara also found an SRC advantage with prenominal RCs, although only in reaction times, not in accuracy. Pizarro-Guevara further found an SRC preference with ambiguous postnominal RCs and no preference with ambiguous prenominal RCs. However, participants arrived at the SRC interpretation much faster than the ORC interpretation regardless of head direction, much as in Wagers et al.'s (2018) study.

Another distinction in headedness relates to whether the head is located within or outside of the RC. In both the prenominal and the postnominal RCs we have discussed so far, the head is located outside of the RC. In contrast to such externally headed RCs (EHRCs), internally headed RCs (IHRCs) have a head located within the RC, as seen in the Korean examples in (27) and (28).

SRCs in Korean (Kim 2004: 1-2)

a. IHRC: Jinho-nun [[totwuk-i tomangka-n]-un kes]-ul capassta Jinho-TOP thief-NOM run.away-IPFV-REL thing-ACC caught 'A/The thief was running away and Jinho caught him.'

b. EHRC: Jinho-nun [[ tomangka-n]-un totwuk]-ul capassta Jinho-TOP run.away-IPFV-REL thief-ACC caught 'Jinho caught a/the thief who was running away.'

ORCs in Korean (Jeon \& Kim 2007: 256)

a. IHRC: John-un [ ${ }_{\mathrm{Np}}$ [chayk-(ul) pilli-n] kes]-ul toli-ecwu-ess-ta John-TOP book-ACC borrow-REL.PST thing-ACC return-AUX-PST-DECL 'John returned the book he borrowed.'

b. EHRC: $\left[_{\mathrm{NP}}[\mathrm{John}-\mathrm{i} \quad\right.$ ilk-ul $] \quad$ chayk $]$ John-TOP read-REL.FUT book 'the book that John will read'

While IHRCs are not as widespread as EHRCs, they are fairly common in languages of East Asia (e.g. Cantonese, Japanese, Korean), languages of the Americas (e.g. Lakota, Quechua), Austronesian languages (e.g. Tagalog), and sign languages (e.g. American Sign Language, German Sign Language). Guasti \& Shlonsky (1995) claimed that IHRCs even occur in child
Figure 2 Summary of RC studies on adult processing in nominative-accusative languages. Each symbol represents a relevant experiment in a study. 
French. Because of the limited availability of IHRCs in well-studied languages, the research on them is scarce, and studies on the subject-object asymmetry are usually limited to EHRCs. Studies in Korean (e.g. Kim 1987; Lee 1991; Cho 1999), however, reveal an interesting difference between EHRCs and IHRCs: children produce more ORCs than SRCs in the form of IHRCs in both naturalistic speech and production experiments, whereas for SRCs they prefer EHRCs. The higher frequency of internally headed ORCs and lower frequency of externally headed ORCs suggests that a head-external ORC construction might be more difficult for children, and that they use IHRCs as an avoidance strategy. Cantonese monolingual children and Cantonese-English bilingual children have also been observed to use IHRCs to bootstrap their acquisition of ORCs (Yip \& Matthews 2007a; b; Chan et al. 2017), as head-internal ORCs in Cantonese share a surface identity with SVO main clauses, ameliorating the difficulty of processing ORCs. More evidence comes from L2 learners of Korean, who have shown different preferences in EHRC and IHRC contexts: while maintaining a subject advantage in EHRCs, the preference for SRCs disappears with IHRCs (Jeon \& Kim 2007). This finding supports the suggestion that IHRCs are syntactically less complex, making internally headed ORCs comparatively easier to process. The findings of this handful of existing studies point to a promising avenue for future research.

\subsection{Resumption}

So far, all the examples presented in this paper use the gapping strategy to form externally headed RCs (i.e. the head leaves its original position empty when displaced out of the clause). There is, in fact, another rather common strategy for relativization: resumption.

The resumption strategy inserts a pronominal element (either pronoun or clitic) to indicate the location of the gap in the RC dependency. Some languages such as Hebrew allow resumption and gapping interchangeably, as in the example in (29).

\author{
Hebrew (Friedmann et al. 2009: 72) \\ Tare li et ha-kof [she-ha-yeled mexbek (oto)] \\ show to-me ACC the-monkey that-the-boy hugs him \\ 'Show me the monkey that the boy is hugging (it).'
}

The use of resumption has been cited as evidence in adult processing and child acquisition of processing difficulty. For adults, syntactic complexity in production shows a correlation in their acceptance of resumption and tendency to use it. Children demonstrate a stronger reliance on the resumption strategy (whether with pronouns, prepositional pronominals, or full NPs) when they are under pressure to produce a more difficult construction, such as ORCs. Hebrew and Mandarin Chinese both allow resumptive ORCs to be used interchangeably with gapped ORCs; children of these languages were found to use the resumptive pronoun strategy predominantly with ORCs, even when the gapping option is available, whereas the proportion of resumptive SRCs was much lower (Hebrew: Varlokosta \& Armon-Lotem 1998; Arnon 2005; Mandarin: Chiu 1996; Hsu et al. 2009).

Even in languages in which resumption is theoretically not an option for relativization, such as English, French, and Spanish (McKee et al. 1998; Labelle 1990; Pérez-Leroux 1995), it can be a popular strategy for children when they are tackling difficult constructions: resumption is rarely found in their SRCs, but very common in their ORCs (with relative pronouns or full NP copies).

Although resumption appears to be a relatively important strategy in child production, its role in child comprehension is less concrete. Some studies have found a strong facilitative role of the resumptive pronoun in children's processing of ORCs (Hebrew: Arnon 2005; Persian: Rahmany et al. 2014), while others have not (e.g. Hebrew: Friedmann et al. 2009; Cantonese: Lau 2016).

\subsection{Morphosyntactic alignment}

Morphosyntactic alignment also influences RC preferences. In languages with nominativeaccusative alignment, intransitive subjects (S) and transitive subjects (A) are treated the sameas nominatives - and direct objects $(\mathrm{O})$ are treated differently—as accusatives—in case marking and agreement. For example, in Japanese, $\mathrm{S}$ and A take the nominative case marker - $g a$ and $\mathrm{O}$ takes the accusative case marker $-o$. In contrast, ergative-absolutive languages treat $\mathrm{S}$ and $\mathrm{O}$ 
alike, differentiating them from A. Ergative-absolutive languages offer an opportunity to tease apart grammatical, morphological, and semantic properties that, in nominative-absolutive languages, converge on the notion of subjecthood (Dixon 1994: 111).

First, ergative-absolutive system allows us to evaluate the effect of morphological cues and whether a subject advantage can be separated from it, as first proposed by Carreiras et al. (2010), who conducted an RC processing study on Basque. According to Carreiras et al., subjects, either intransitive or transitive, are in an unmarked class, while transitive objects are in a marked class in nominative-accusative languages. In ergative-absolutive languages, on the other hand, intransitive subjects and transitive objects are grouped in an unmarked class, while transitive subjects are in a marked class. They proposed that the processing advantage is associated with morphological unmarkedness, which leads to a subject advantage in nominative-accusative languages but an object advantage in ergative-absolutive languages. They did not, however, offer further explanation of why morphological unmarkedness leads to a processing advantage. Polinsky et al. (2012) put forward a slightly different proposal to explain how a morphological advantage manifests in ergative-absolutive languages based on Marantz's (1991) notion of "dependent" and "independent" cases. In nominative-accusative languages, nominative is an independent case and accusative is a dependent case. That is, a clause can have a nominative argument without also having an accusative argument, but an accusative argument can only occur if there is a nominative argument. Hence, an accusative argument strongly signals that the clause is transitive and that there should be a nominative argument, while the presence of a nominative argument itself does not signal the presence of an accusative argument. In $\mathrm{RCs}$, too, an accusative argument facilitates the prediction of the presence of a nominative argumet, except when the nominative argument is absent because of the gap, which in turn helps anticipate an upcoming nominative head noun. In ergative-absolutive languages, on the other hand, absolutive is an independent case and ergative is a dependent case; therefore, an ergative argument can signal the presence of an absolutive gap, giving a potential advantage to an (absolutive) ORC (Polinsky et al. 2012; Longenbaugh \& Polinsky 2016). More details on these studies are provided in 4.3.1.

Second, languages with syntactic ergativity offer a further opportunity to tease apart grammatical and processing preferences for subjects, as will be discussed in 4.3.2. In these languages, the relativization of ergative subjects is treated differently from the relativization of absolutive subjects/objects (e.g. Tongan, Ono et al. 2020a; b), or may not be allowed without additional measures (e.g. Q'anjob'al Mayan, Gagliardi et al. 2013; Clemens et al. 2015). Because absolutives in ergative-absolutive languages are more accessible to syntactic processes, including relativization, they allow us to explore the question of whether a grammatical advantage translates to a processing advantage (Fox 1987).

Figure 3 summarizes findings on the RC preferences of ergative languages. ${ }^{3}$

\begin{tabular}{|c|c|c|c|c|c|}
\hline \multicolumn{5}{|c|}{$\begin{array}{l}\text { Ergative Languages } \\
\text { RC order }\end{array}$} & \multirow[t]{3}{*}{$\begin{array}{l}\text { Key } \\
\text { Domain } \\
\text { ○ Production } \\
\text { C Comprehension } \\
\text { Preference } \\
\text { S S preference } \\
\text { O No preference } \\
\text { O preference } \\
\nabla \text { Preference not clear }\end{array}$} \\
\hline Prenominal & $\begin{array}{r}\text { Avar } \\
\text { Basque }\end{array}$ & 0 & ○ & 000 & \\
\hline Postnominal & $\begin{array}{r}\text { Mayan (Ch'ol) } \\
\text { Mayan (Q'anjob'al) } \\
\text { Niuean } \\
\text { Tongan }\end{array}$ & $?$ & 0 & - & \\
\hline & & $\mathrm{S}>\mathrm{O}$ & $\mathrm{S}=\mathrm{O}$ & \multicolumn{2}{|r|}{$\mathrm{O}>\mathrm{S}$} \\
\hline
\end{tabular}

In what follows, we first discuss morphologically ergative languages and then discuss syntactically ergative languages. We acknowledge that there are languages that show construction-specific ergativity, such as Georgian (Lau et al. 2018; Foley 2020) and Hindi-Urdu (Hansen 1986; Vasishth \& Lewis 2006), but we do not further discuss these split ergative languages. 


\subsubsection{Morphologically ergative languages}

Studies on morphologically ergative languages demonstrate the role of morphology in the acquisition and processing of RCs. For instance, Basque (SOV) groups $\mathrm{S}$ and $\mathrm{O}$ as the unmarked category-absolutive-and treats A as a marked category-ergative. As explained above, absolutive is an independent case while ergative is a dependent case. Both the unmarked status and independent nature of the absolutive can give rise to an (absolutive) object advantage.

Basque comprehension studies show a preference for absolutive ORCs (30c) over ergative SRCs (30b) in children (Gutierrez-Mangado 2011; Gutierrez-Mangado \& Ezeizabarrena 2012) and adults (Carreiras et al. 2010). While resource-based effects could account for this object preference (Basque uses prenominal RCs), another plausible explanation is the morphological unmarkedness of absolutive O (Carreiras et al. 2010; Gutierrez-Mangado 2011; GutierrezMangado \& Ezeizabarrena 2012), because an overtly marked ergative argument in a prenominal RC unambiguously signals an ORC. Nevertheless, children's and adults' production reveals a subject advantage (Gutierrez-Mangado \& Ezeizabarrena 2012), presumably because production is less influenced by morphological cuing effects than comprehension.

$$
\begin{aligned}
& \text { Basque (Gutierrez-Mangado \& Ezeizabarrena 2012: 5, ex. 7) } \\
& \text { a. SOV } \\
& \text { Mutiko-a-k pinguinu-a- } \varnothing \text { garbi-tzen du } \\
& \text { boy-the-ERG penguin-the-ABS wash-IPFV AUX } \\
& \text { 'The boy is washing the penguin.' } \\
& \text { b. SRC (Ergative subject gap) } \\
& \text { [_pinguino-a- } \varnothing \text { garbi-tzen du-en] mutiko-a- } \emptyset^{4} \\
& \text { penguin-the-ABS wash-IPFV AUX-REL boy-the-ABS } \\
& \text { 'the boy that is washing the penguin' } \\
& \text { ORC (Absolutive object gap) } \\
& \text { [pinguino-a-k - garbi-tzen du-en] mutiko-a- } \varnothing \\
& \text { penguin-the-ERG wash-IPFV AUX-REL boy-the-ABS } \\
& \text { 'the boy that the penguin is washing' }
\end{aligned}
$$

Avar, another morphologically ergative language with SOV word order and prenominal RCs, offers additional insights (Polinsky et al. 2012). Like Basque, Avar zero-marks absolutive objects and overtly marks ergative subjects. The suffix-marked ergative subject signals a clause-mate absolutive argument, but not vice versa. Furthermore, Avar verbs agree in noun class with the absolutive; thus, verb morphology also cues the existence and identity of the absolutive co-argument.

Avar (Polinsky et al. 2012: 271-276, ex. 7-9)

a. $\quad$ SRC (Ergative subject gap)

[_foloqana-y yas- $\varnothing \quad$ repetici-yal-de $\quad$ y-ač:-un $\quad$ y-ač'-ara-y] unmarried-II girl-ABS rehearsal-OBL-LOC II-bring-GER II-come-PRTCP-II artistka- $\varnothing[\ldots]$ actress-ABS

'The actress [that _ brought the young girl to the rehearsal] [...]'

b. ORC (Absolutive object gap)

[xalq'iya-y artistka-yał _ repetici-yal-de y-ač:-un y-ač'-ara-y] people's-II actress-ERG rehearsal-OBL-LOC II-bring-GER II-come-PRTCP-II yasi- $\varnothing \quad[\ldots]$

girl-ABS

'The girl [ that the distinguished actress brought _ to the rehearsal] [...]'

c. Intransitive SRC (Absolutive subject gap)

[_xalq'iya-y artistka-yal-da-ask'o-y repetici-yal-de č':u-n people's-II actress-OBL-LOC-near-II rehearsal-OBL-LOC standing-GER y-ik'-ara-y] yas- $\varnothing$ II-be-PRTCP-II girl-ABS

'The girl [ that _ stood next to the distinguished actress at the rehearsal ] [...]'

Although Polinsky et al. found no processing difference between ergative SRCs (31a) and absolutive ORCs (31b), they argued that Avar has a subject (i.e. A-argument) advantage that

4 The ergative subject 'the boy' no longer bears ergative case as it takes absolutive case in the matrix clause. But the RC is missing an ergative subject, compared with (30a, c), signaling this is the ergative gap. 
is suppressed by the morphological advantage for the absolutive (i.e. O-argument). Similar arguments were made in Longenbaugh \& Polinsky's (2016) study on Niuean, which found an advantage for absolutive SRCs but no difference between ergative SRCs and absolutive ORCs.

These findings - the comprehension-production asymmetry in Basque and the lack of a clear subject advantage in Avar and Niuean—suggest that morphological cuing effects are independent of the subject advantage, and these effects could neutralize or counteract the subject advantage in ergative languages. In fact, Clemens et al. (2015) demonstrated that adult speakers of Ch'ol Mayan show a clear processing preference for SRCs: higher accuracy, faster response times, and a tendency to interpret ambiguous RCs as SRCs. In Ch'ol, grammatical relations are marked on the predicate but not on the NP, which Clemens et al. used to argue that case cuing, but not predicate marking, mitigates the subject advantage.

The few studies on morphologically ergative languages show that the effects of morphology exist independent of the subject advantage, and that these effects can counteract the subject advantage.

\subsubsection{Syntactically ergative languages}

Some languages manifest ergativity syntactically; in such cases, relativization is restricted to absolutive arguments. Essentially, these languages can only relativize absolutives ( $\mathrm{S}$ and $\mathrm{O}$ ), and special constructions have to be used to relativize ergatives (A).

In Q'anjob'al Mayan, a syntactically ergative VSO language, absolutive $\mathrm{O}$ can be relativized directly, but ergative A cannot. As shown in (32), the predicate must be converted to intransitive by using "Agent Focus" (AF) to relativize the A-argument; after relativization, the ergative subject no longer triggers agreement morphology in the AF verb (as it would in a transitive verb).

Q'anjob'al Mayan (Clemens et al. 2015: 438, ex. 17a, 18-20)

a. Transitive clause

Max- $\varnothing \quad$ y-uk' ix ix kapey.

PFV-3.ABS 3.ERG-drink DET woman coffee

'The woman drank coffee.'

b. ORC (Absolutive object gap)

Max jay ix ix [maxh-el-a' ].

PFV arrive DET woman PFV 2.ERG-See-TR

'The woman [ who you saw _] arrived.'

c. Ungrammatical SRC (ergative subject gap)

*Max jay ix ix [max-ach y-il-a' ].

PFV arrive DET woman PFV-2.ABS 3.ERG-see-TR

(Intended: 'The woman [ who _ saw you ] arrived.')

d. Grammatical SRC (subject gap with agent focus; AF-SRC)

Max jay ix ix [max-ach il-on-i _].

PFV arrive DET woman PFV-2.ABS see-AF-INTR

'The woman [ who _ saw you ] arrived.'

Gagliardi et al. (2013) found no (significant) difference between AF-SRCs and ORCs in the production of RCs by child and adult speakers of Q'anjob'al Mayan. This lack of difference indicates competition between the grammatical system, which disprefers A-argument extraction, and a processing preference for the A-argument. Clemens et al. (2015) offered further support, showing a subject preference in adult speakers' comprehension of ambiguous and unambiguous RCs in Q'anjob'al Mayan.

Another syntactically ergative language, Tongan (VSO; postnominal RCs), permits the relativization of an ergative subject with an obligatory resumptive pronoun in the gap position. Ono et al.'s (2020a) self-paced reading task showed a Tongan preference for absolutive ORC over ergative SRC. They suspected, however, that it might be due to potential ambiguity between the resumptive pronoun and the regular subject pronoun, which would cause slowdown in SRC processing during the reanalysis of an initial misinterpretation. In a follow-up experiment, Ono et al. (2020b) indeed found a slowdown at the resumptive pronoun in ergative SRCs. They also found slowdown at the ergative NP position in absolutive ORCs but not absolutive SRCs. They considered these results evidence for their argument of a subject advantage in Tongan RCs. That said, the subject advantage was not strong enough to outweigh the processing cost of the 
resumptive pronoun in ergative SRCs. ${ }^{5}$ In Tongan, too, much like other ergative languages, different forces are in competition with a subject advantage, neutralizing its effects.

While the scarcity of RC studies on ergative languages prevents firm conclusions, the existing studies seem to support the presence of some kind of processing preference for subjectswhich, however, may be weakened by morphological advantages associated with the absolutive and/or grammar disfavoring the extraction of ergatives. Our knowledge that this possibility exists relies on the opportunity provided only by ergative languages to disentangle distinct properties of subjecthood. More research on ergative languages is needed to further develop our understanding of where the processing preference for subjects, which is distinct from morphological or grammatical advantages, comes from. ${ }^{6}$

\section{Cross-methodological considerations}

Many methods are employed to examine RC processing and acquisition. In the following subsections, we summarize four types of comprehension task-picture/character selection (5.1), self-paced reading (5.2), eye-tracking while reading (5.3), and event-related potential (5.4)—followed by an overview of production tasks (5.5).

\subsection{Picture selection and character selection}

Picture selection (or sentence-picture matching) and character selection tasks are often used to study RC acquisition. Their design is similar: children see two pictures of the same pair of characters performing the same action, but with reversed thematic roles in each picture (Figure 4).

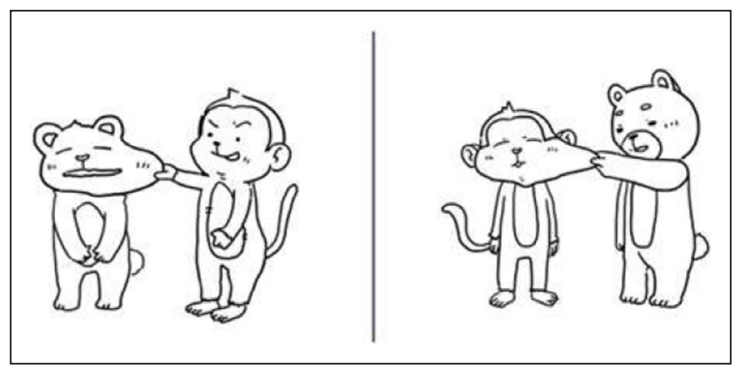

In Figure 4, both pictures have a bear and a monkey, and both illustrate a pinching event. The only difference between the two pictures is who plays which role in the event: in one picture, the monkey is the agent and the bear is the patient of the pinching event; in the other, their roles are reversed.

Some picture selection tasks use three pictures, with the third as a distractor. Others use only one picture with three (groups of) participants, as shown in Figure 5.

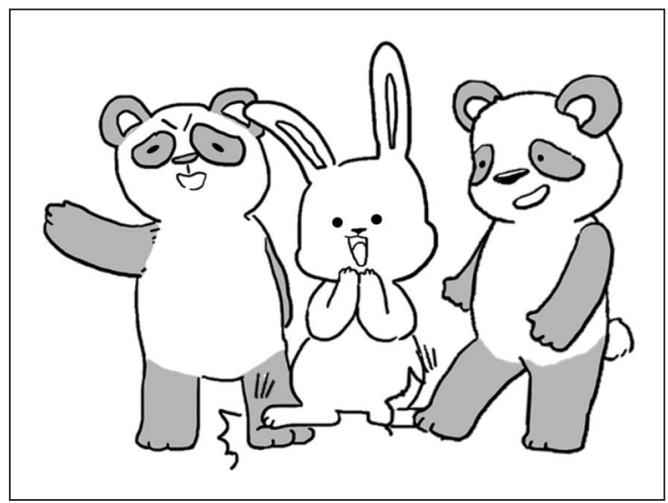

The pictures' reversibility is key. The child language acquisition literature generally assumes that children will rely on lexical semantics if they lack the syntax to understand a sentence. For this reason,
Figure 4 Example visual stimulus for picture/character selection task.

Figure 5 Example visual stimulus for picture/character selection task with three participants.

\footnotetext{
5 In addition, Otaki et al. (2020) found an ergative subject advantage in the acquisition of wh-questions in Tongan, which are considered pseudo-clefts with headless RCs. 
the pictures are minimally different: they can only be differentiated by the correct interpretation of the sentence. The reversibility of the pictures ensures the children use their syntactic knowledge.

The difference between picture selection and character selection is in the choice set. Picture selection requires participants to pick the picture that best matches the sentence. However, the nature of an RC is not to identify an event but to pick one entity from a set; this pragmatic expectation is not met by the design of the picture selection task. The method has been criticized for its inefficacy because choosing the picture with the target is not sufficient to show that children understand the target referent of the RC (Arnon 2005; Adani 2011). Therefore, in some RC studies, participants are instructed to choose the character (not the picture) described by the sentence, thereby fulfilling the pragmatic presuppositions of an RC.

As mentioned, the reversal error provides evidence on children's RC comprehension. For example, given the target utterance in (33), children might wrongly choose the pinching monkey instead of the monkey that is being pinched, as shown in Figure 6.

$$
\text { Target: The monkey that the bear is pinching }
$$

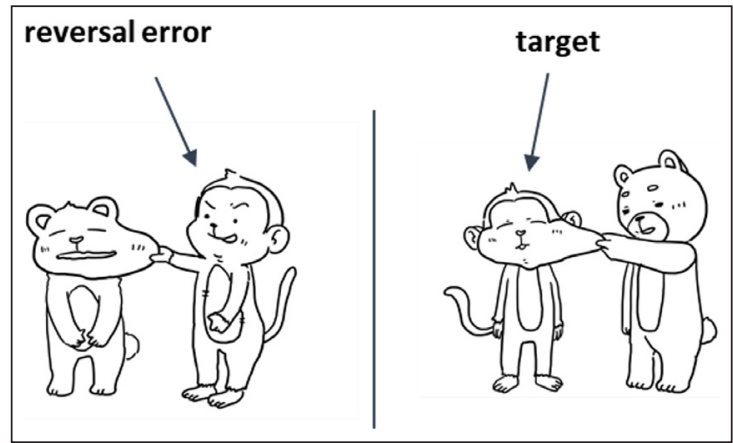

The reversal error is often observed when RC constituents do not follow canonical word order, which suggests that children who have not yet acquired RC syntax rely on canonical word order to interpret sentences. Thus, they attribute the first NP in a sentence as the agent (e.g. Diessel \& Tomasello 2005; Benţea 2012), and apply the relative positions of the predicate and arguments to the RC. For example, in English (SVO), children would assume that the argument that comes first and precedes the verb is the subject/agent of the event (Pozzan et al. 2016; Abbot-Smith et al. 2017).

If these tasks are administered off-line, with or without a computer (e.g. using printed pictures), error rate is the dependent variable. When they are administered on-line, reaction times can be measured with the use of mouse- or touch-tracking, allowing choice latency to be assessed (Freeman \& Ambady 2010; Wagers et al. 2018). Eye-tracking can also be used to measure gaze fixation and duration in addition to accuracy and reaction times (Stern et al. 2019; MacDonald et al. 2020).

The relative simplicity of this paradigm gives it advantages such as the flexibility of being administered with or without a computer, on-line or off-line. Being picture- and audio-based, it is suitable for participants with low or no reading skills. Results obtained from picture selection are comparable to those obtained from self-paced reading (Clemens et al. 2015; Longenbaugh \& Polinsky 2016), which we discuss next.

\subsection{Time-sensitive word-window paradigms: Self-paced reading and maze tasks}

The self-paced reading paradigm is popular in adult psycholinguistic research. Participants read a sentence word-by-word or phrase-by-phrase, pressing a key to advance to the next word/phrase. (A child-friendly version is self-paced listening, where button presses initiate audio segments.) The key press latencies are assumed to reflect processing difficulty at different points in a sentence, and correlate with the time course of the processing of the sentence.

Gibson (1998) demonstrated a correlation between reading times and processing costs in the incremental processing of long-distance RC dependencies. Longer reading times indicate more mental effort to hold the constituents in mind until the processor encounters and integrates the information needed to resolve the dependency. In English, the point of integration occurs (as shown by increased reading times) at the verb. Longer reading times with ORCs (at both RC verb and matrix verb) compared to SRCs are considered evidence for the subject advantage in English.
Figure 6 Reversal error in character selection for the example in (33). 
Maze tasks are also designed to identify points of difficulty during incremental comprehension (Nicol et al. 1997; Forster et al. 2009; Qiao et al. 2012). Participants choose between two possible sentence continuations, pressing a key to indicate their choice and to advance to the next word. Measuring the integration time for each word in a sentence pinpoints the location(s) of processing difficulty.

The location of reading time differences has been used to support theoretical claims and as evidence for RC preferences, especially in languages where other evidence is unclear. For example, Hsiao \& Gibson (H\&G; 2003) reported an object preference in Mandarin Chinese based on longer reading times, in doubly embedded RCs only, at a pre-relativization region in SRCs. With simple RCs, they found no significant difference. Subsequent works, however, question H\&G's results. Lin \& Bever (2006) argued that the differences H\&G reported were unlikely, given their location, to reflect processes involved in resolving RC dependencies. In their own study, Lin \& Bever found significantly faster reading times at the relativizer and the head noun for SRCs, which they took to reflect easier gap-filler integration, thus supporting a subject advantage for Mandarin. Vasishth et al. (2013) attempted to replicate H\&G in two experiments; the first failed to replicate H\&G's findings, instead finding a subject advantage at the head noun. The second found an object advantage, but the significant difference was at the relativizer, which does not support H\&G's memory-based proposal. Vasishth et al. also criticized $H \& G$ for violating the assumptions of their own statistical model, and showed that the claimed effect disappears if all the model's assumptions are satisfied. Table 2 summarizes reported reading time patterns from RC studies on Mandarin, illustrating the processing advantage (or no advantage) observed in each window throughout the sentence. Studies are inconsistent on

\begin{tabular}{|c|c|c|c|c|c|}
\hline Study & RC & de & HN & $\mathrm{HN}+1$ & Claim \\
\hline \multicolumn{6}{|l|}{ SELF-PACED READING } \\
\hline Lin 2006 & n.s. & $\mathrm{S}$ & $\mathrm{S}$ & - & $\mathrm{S}$ \\
\hline Li et al. 2010 (S-modifying) & n.s. & n.s. & $\mathrm{S}$ & n.s. & $\mathrm{S}$ \\
\hline Li et al. 2010 (0-modifying) & n.s. & n.s. & $\mathrm{S}$ & - & $\mathrm{S}$ \\
\hline Vasishth et al. 2013 Experiment 1 & - & n.s. & $\mathrm{S}$ & n.s. & $\mathrm{S}$ \\
\hline Vasishth et al. 2013 Experiment 2 & - & n.s. & $\sim \mathrm{S}$ & $\mathrm{S}$ & $\mathrm{S}$ \\
\hline Jäger et al. 2015 Experiment 1 & $\mathrm{~S}$ & n.s. & n.s. & $\mathrm{S}$ & $\mathrm{S}$ \\
\hline Cheng et al. 2018 (0 digit recall) & n.s. & $\mathrm{S}$ & n.s. & n.s. & $\mathrm{S}$ \\
\hline Hsiao \& Gibson 2003 (singly-embedded RC condition) & 0 & n.s. & n.s. & n.s. & $\mathrm{O}$ \\
\hline Chen et al. 2008 (Low Working Memory) & 0 & n.s. & n.s. & n.s. & $\mathrm{O}$ \\
\hline Lin \& Garnsey 2011 & 0 & 0 & 0 & 0 & 0 \\
\hline Cui 2013 (S-modifying) & n.s. & n.s. & 0 & n.s. & 0 \\
\hline Gibson \& Wu 2013 & n.s. & 0 & 0 & n.s. & $\mathrm{O}$ \\
\hline Vasishth et al. 2013 Experiment 3 & - & 0 & $\sim 0$ & n.s. & 0 \\
\hline Wu \& Juffs 2016 (null context) & n.s. & 0 & n.s. & 0 & $\mathrm{O}$ \\
\hline He et al. 2017 (S-modifying, youths) & n.s. & n.s. & n.s. & n.s. & 0 \\
\hline He et al. 2017 (S-modifying, elders) & n.s. & n.s. & 0 & n.s. & $\mathrm{O}$ \\
\hline Xu et al. 2019 Experiment 1 & 0 & n.s. & n.s. & - & $\mathrm{O}$ \\
\hline Xu et al. 2019 Experiment 2 & n.s. & 0 & n.s. & - & $\mathrm{O}$ \\
\hline Chen et al. 2008 (High Working Memory) & n.s. & n.s. & n.s. & n.s. & n.s. \\
\hline Cui 2013 (0-modifying) & n.s. & n.s. & n.s. & n.s. & n.s. \\
\hline He et al. 2017 (0-modifying, youths) & n.s. & n.s. & n.s. & $\mathrm{S}$ & n.s. \\
\hline He et al. 2017 (0-modifying, elders) & n.s. & n.s. & n.s. & $\mathrm{S}$ & n.s. \\
\hline \multicolumn{6}{|l|}{ MAZE TASK } \\
\hline Qiao et al. 2012 Experiment 1 (Gmaze) & 0 & $\mathrm{~S}$ & n.s. & - & $\mathrm{O}$ \\
\hline Qiao et al. 2012 Experiment 2 (Lmaze) & 0 & n.s. & n.s. & - & 0 \\
\hline
\end{tabular}

Table 2 Mandarin RCs: Findings from self-paced reading.

Note. S: subject advantage; o: object advantage; n.s.: difference does not reach significance, interpreted as no S-O asymmetry; S/O: marginal advantage; -: results not reported. 
the point where subject-object asymmetry is observed: effects have been found at parts of the $\mathrm{RC}$, at the whole RC region (RC), at the relativizer (de), at the head noun (HN), and only in spill-over regions after the head noun $(\mathrm{HN}+1)$.

\subsection{Eye-tracking}

Most eye-tracking studies on RCs use a reading paradigm, in which a stimulus sentence is presented on a screen. In self-paced reading, a sentence is presented piece-by-piece. For eye-tracking, the sentence is presented in full for a more natural reading experience. While the participant reads, the eye-tracker records the pattern of eye fixations, providing precise information on reading latencies for each word, thus tapping into the incremental processing of RC dependencies.

The equivalent of reading latencies in eye-tracking studies is gaze duration or total fixation. Gaze duration, sometimes also taken as equivalent to first-pass fixation, measures the total duration of fixation on a word before the eye leaves the region for the first time. Total fixation is the sum of all fixations on a word (i.e. all first-pass and subsequent re-reading times).

Another measure is rate of regression. Regression refers to fixations from re-reading a word; regression rate corresponds to the probability of returning to the target region after the first reading. Higher regression rates indicate difficulty in processing a word or integrating it into a structure. Regression-path duration, the total amount of fixation time on all target and pretarget regions, is also sometimes reported.

Studies consistently show higher regression rates for more difficult types of RCs. Baudiffier et al. (2011) found increased regressions in ORCs at the RC region, indicating an initial subject analysis during French RC processing. Betancort et al. (2009) found more regressions out of the final region of the more difficult type (i.e. ORC) in the dispreferred animacy configuration (I-A condition) in Spanish. They explained the longer total fixation time and higher regression rate for ORCs as indicating the reanalysis required after initial misinterpretation as an SRC. In Korean, Kwon et al. (2010) found longer regression-path duration and re-reading times for ORCs than SRCs.

\subsection{Event related potential (ERP)}

ERP is another time-sensitive measure employed by RC studies to pinpoint the location of difficulty during incremental processing of RC dependencies. It is also used to locate the parts of the brain involved in processing complex syntactic structures.

The two most common observations related to the processing of long-distance dependencies such as RCs are left anterior negativity (LAN) and the P600 effect. LAN is a negative-going wave with greater distribution in the anterior (than the posterior) region, and is often (but not always) left-lateralized. LAN is related to working memory load; observed between the head and the gap in RC processing studies, it is taken to reflect the processing cost of the load on working memory. For example, King \& Kutas (1995) reported a bilateral frontal slow negative potential for the entire RC region, and a phasic LAN effect immediately following the gap in English ORCs. They interpreted these results as evidence for ORCs incurring higher memory costs during processing.

The P600 is a positive-going deflection that peaks at about 600ms (or in the range of 500$900 \mathrm{~ms}$ ) after stimulus onset. It often has a broad bilateral distribution over the head, with a maximum along the centro-posterior region. The P600 effect is taken to index processes of syntactic integration or syntactic reanalysis; an increase in positivity indicates an increase in integration difficulty.

Much like other processing paradigms, ERP studies also report higher processing costs associated with ORCs (e.g. Mecklinger et al. 1995; Ueno \& Garnsey 2008; Kwon et al. 2013; Bulut et al. 2018; Lau et al. 2018). ${ }^{7}$ 


\subsection{Production}

While most processing studies and many acquisition studies on RCs focus on comprehension, production also shows RC asymmetry. It is important to measure both, as some studies report comprehension-production asymmetry (Gutierrez-Mangado \& Ezeizabarrena 2012).

Probably the most informative task type involves elicited production. One way to elicit production is to use a picture description task, in which participants describe pictures that provide context for obligatory RCs (Hamburger \& Crain 1982; Zukowski 2009; Kim \& O'Grady 2016). Another elicitation technique is referred to as a preference task (e.g. Novogrodsky \& Friedmann 2006). Based on a contrastive context provided orally, participants are asked to say which option they prefer, requiring them to provide individuating information. These tasks circumvent comprehension-specific issues such as main clause ambiguity with prenominal RCs (see Section 4.1), and the data they produce can reveal sources of difficulty that comprehension tasks miss. The data are messier, however; the tasks allow speakers to produce ambiguity and employ avoidance strategies (Lee-Ellis 2011). Production data require careful analysis, and "accuracy," however defined, tends to be lower due to the speakers' freedom to say whatever they choose.

A more controlled production task type is (elicited) imitation (or sentence repetition), in which participants are asked to repeat what they hear (Slobin \& Welsh 1973; Lust et al. 1998). The task is easy, and is usually used with young children or other populations (e.g. aphasics) for whom elicited production is difficult. Participants presumably do not simply take in and reproduce what they hear; rather, they process and analyze it, reconstructing it in their repetition. Because they have to make use of their grammar for the reconstruction, what they say reflects the syntactic knowledge/structure available to them. There is a confound, however-in order to imitate a sentence accurately, you have to comprehend it, so the task involves comprehension as well as production (Zukowski 2009).

Sentence combination tasks offer another somewhat controlled way to investigate production. Participants combine sentences such as "The man is coming today." and "The man painted the house last month." (Doughty 1991: 442). This is a common procedure in L2 studies, often as a written task, perhaps because it is easily done in class.

$\mathrm{RC}$ research also employs corpus analysis. Corpora usually contain naturalistic or spontaneous speech, providing useful information about what structures speakers-adults and children-use and hear most often. The limitations of corpus data include lack of control over the context. In addition, emergence may not be equivalent to acquisition (Lee-Ellis 2011: 60). Elicited narratives have similar shortcomings, but can provide more control.

\section{Clinical populations}

$\mathrm{RC}$ research also has a role in studies with clinical populations with linguistic delay, deficit, or loss. It is not our intention to misrepresent the differences among these heterogeneous groups. Nevertheless, the studies referenced in this section share a common thread.

First, as Figure 7 shows, numerous studies on clinical populations report a subject advantage, albeit with considerable individual variation. ${ }^{8}$

Second, RC asymmetry research deepens our understanding of language deficits. One recurring question is whether language deficits occur in representation or in processing. For example, some argue for syntactic impairment in aphasics (e.g. Caplan \& Futter 1986; Grodzinsky 1986; 1989; Friedmann \& Shapiro 2003), and in people with specific language impairment (SLI; Friedmann \& Novogrodsky 2004; Novogrodsky \& Friedmann 2006; de López et al. 2014; Adani et al. 2016) and Williams syndrome (WS; Zukowski 2009). They may therefore rely on heuristics and assign thematic roles linearly (e.g. first NP as the agent) in non-canonical sentences, causing errors. This hypothesis accounts for why aphasics show an ORC preference in Cantonese and Mandarin, in which the prenominal ORCs resemble the canonical word order of the language (Section 4.1). Other researchers argue for processing impairment in aphasics (Lukatela et al. 1995), poor readers (Mann et al. 1984; Smith et al. 1989; Bar-Shalom et al. 1993), and 


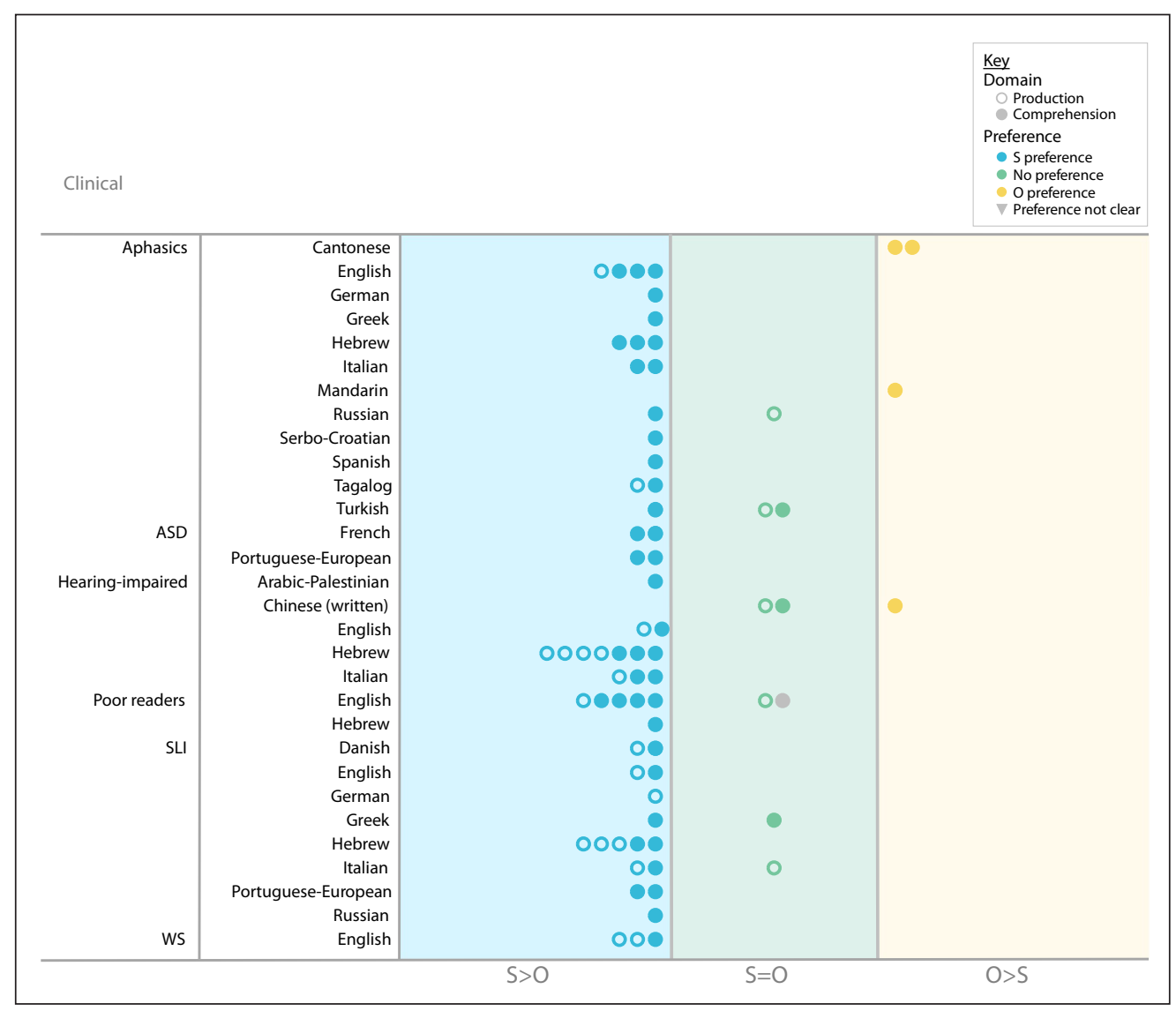

people with SLI (Rakhlin et al. 2016). Based on parallelism between the target population and counterparts without language deficits (e.g. healthy adults, good readers, typically developing children), the claim is that their performance differs in quantity, not quality. Others suggest a hybrid approach (Garraffa \& Grillo 2008; Rakhlin et al. 2016). Rakhlin et al. (2016), based on their research on SLI, pointed out that resource deficits could account for much but not all of their results. They suggested that any theoretical account for RC asymmetry should be informed by resource-based accounts, with additional considerations for other factors (e.g. the use of grammar).

These studies illustrate the broad theoretical and practical implications of the question of RC asymmetries. The fact that different clinical populations show parallel results between them and with non-clinical populations is an important contribution to the larger body of RC research, because it suggests a common underlying source of the asymmetry, although whether it is the sole source is a separate question. At the very least, clinical populations offer test cases in which cognitive resources are limited. It is therefore important for researchers across fields to communicate with each other and establish common ground for discussions.

A better understanding of the basis of RC asymmetry could also benefit clinical populations by (potentially) providing diagnostic tools. RCs have been used to evaluate ability in complex syntax and structural processing in people with autism spectrum disorder (ASD; Durrleman et al. 2015; Durrleman, Marinis \& Franck 2016) and WS (Zukowski 2009).

\section{Second language acquisition and multilingualism}

The previous sections focused on monolingual speakers and/or those who identify as native speakers of the language. Yet the phenomenon of subject-object asymmetry has inspired much research on whether the NPAH might predict the order of acquisition and/or processing advantages for diverse multilingual populations, the focus of this section. Many of these studies support the NPAH - albeit with a bias from the overwhelming focus on learners of English as a second language-but the findings are not entirely consistent. Consider the variation seen in the L1 studies (Section 4). The studies briefly reviewed in this section involve a combination of two or three of these different languages, and additional factors must be considered; for example, cross-linguistic influence between languages, relative proficiency of languages (which may impact processing resources), age of onset, length of exposure, and so on.
Figure 7 Studies on clinical populations (ASD: autism spectrum disorder; SLI: specific language impairment; WS: Williams syndrome). Each symbol represents a relevant experiment in a study. 
In this section, we present these populations in roughly three categories: second language (L2) learners, heritage language speakers, and bilingual/trilingual children. Admittedly, these lines are blurry, but the distinction here respects the framing of the authors of the original studies.

\subsection{Second language learners}

This section summarizes studies that have reported on second/foreign language learners and speakers. Although a few of the studies include child learners, naturalistic learners, and heritage speakers, most of the participants are typical adult classroom learners. Figure 8 illustrates the findings on the RC preferences of different L2 learner populations. ${ }^{9}$

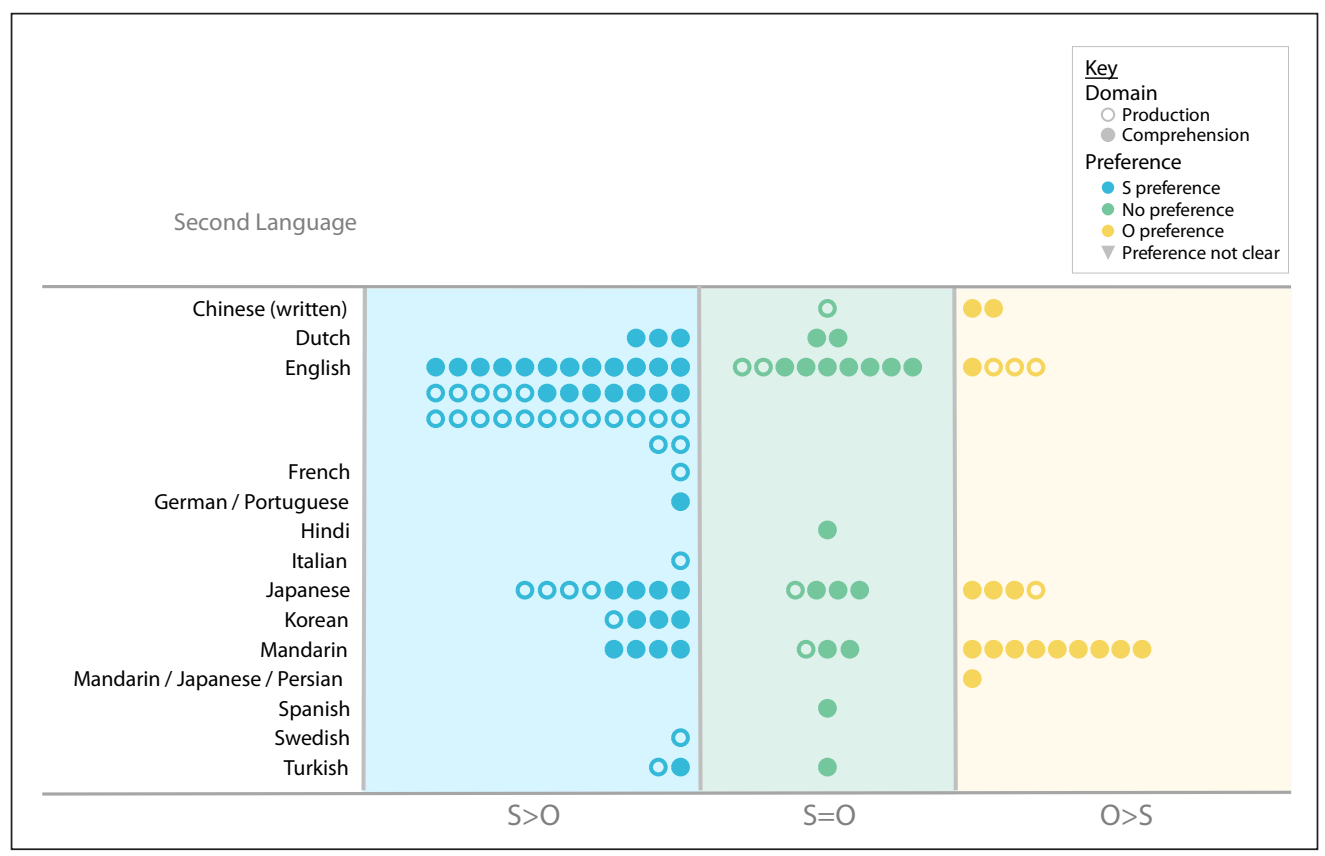

A comprehensive review of L2 studies warrants a separate paper, but we would like to highlight several studies that have investigated the effects of instruction on the (order of) acquisition of RCs; that is, whether teaching RCs in one position of the NPAH facilitates learning of RCs in other positions, and whether the direction of such effects follows the hierarchy (Gass 1982; Eckman et al. 1988; Doughty 1991; Hamilton 1994; Croteau 1995; Ammar \& Lightbown 2005; Yabuki-Soh 2007). These studies have found that, when learners receive instruction about RCs of a certain position, they can generalize the knowledge to higher, but not to lower, positions on the NPAH. Eckman et al. (1988), Croteau (1995), and Ammar \& Lightbown (2005), for example, showed that learners who were taught ORCs would also be able to understand and produce SRCs without instruction on SRCs. The same was not necessarily true the other way around-learners who received instruction on SRCs did not improve much on ORCs in Eckman et al. (1988). The finding that the effects of instruction may follow the NPAH illuminates an additional facet of the subject-object asymmetry.

\subsection{Heritage language learners}

Heritage language speakers or learners refer to those who speak a minority language of a society, such as a home language in an immigrant family, as their L1, and speak a majority language of the society as their L2 (Polinsky 2008). Typically, their L2 eventually becomes more dominant than their L1. A few studies explore the RC asymmetry in heritage Egyptian and Palestinian Arabic (Albirini et al. 2014), Levantine Arabic (Albirini 2018), Korean (O'Grady et al. 2001; Lee-Ellis 2011), Russian (Polinsky 2008; 2011), and Spanish (Stern et al. 2019). Figure 9 presents a summary of the findings of the studies. ${ }^{10}$ While the results converge on a subject advantage, all such studies to date involve heritage speakers whose dominant language is English.
Figure 8 Studies on second language learners. Each symbol represents a relevant experiment in a study. 


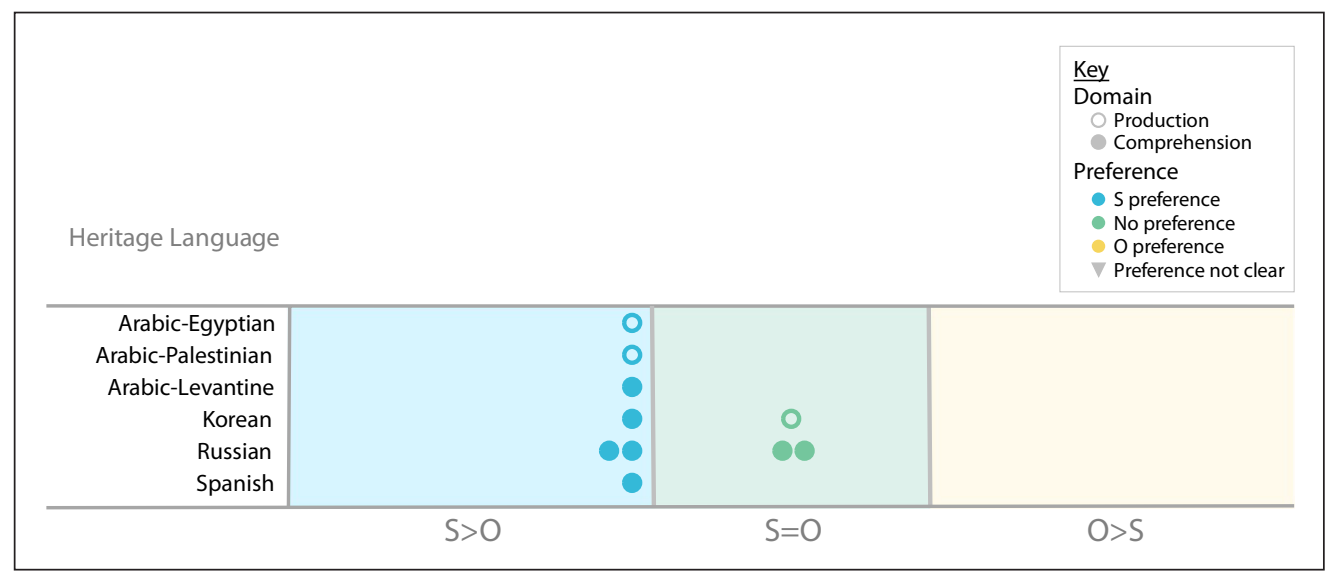

While the number of these studies is still relatively small, heritage speakers offer unique opportunities to expand our exploration of the RC asymmetry phenomenon, in relation to a more general inquiry of what heritage grammar looks like. Is it different from the grammar of monolingual native speakers, and if so, why? There are several reasons why heritage grammar may be divergent. First, because their L2 is more dominant than their L1, heritage language speakers are susceptible to transfer from the L2 instead of-or in addition to-the L1. Second, due to limited L1 input, they might not learn certain structures, resulting in incomplete L1 acquisition. Third, their L1—whether fully acquired or not-may go through attrition as their L2 becomes more dominant. Polinsky $(2008 ; 2011)$ tackled these questions by comparing the comprehension of SRCs and ORCs by adult and child monolingual and heritage speakers of Russian. While both monolingual groups and child heritage speakers performed at ceiling, adult heritage speakers showed an asymmetry, indicating that divergence in heritage grammar is due to language attrition rather than to incomplete acquisition.

In addition, heritage speakers have more exposure in naturalistic settings and are often untutored; this means they are more likely to have regular exposure to complex structures like RCs and may rely less on explicit knowledge than classroom-based L2 learners (Lee-Ellis 2011).

\subsection{Bilingual/Trilingual children}

This section summarizes studies framed as being on bilingual and/or trilingual children (Figure 10). ${ }^{11}$ We introduce these studies separately as many of them do not quite fit the mould of L2 studies or heritage studies in a traditional sense. We also include studies that could have well been introduced in previous sections on child L2 learners (e.g. Scheidnes \& Redmond 2019 on L1-English L2-French children) and heritage speakers (e.g. Hu \& Guasti 2017 on MandarinItalian bilingual children in Italy; Tsoi et al. 2019 on Mandarin-English bilingual children in Australia).

\begin{tabular}{|c|c|c|c|c|c|}
\hline $\begin{array}{l}\text { Multilinguals } \\
\text { Multilingual Condition }\end{array}$ & & & & & $\begin{array}{l}\frac{\text { Key }}{\text { Domain }} \\
\text { O Production } \\
\text { Comprehension } \\
\text { Preference } \\
\text { S preference } \\
\text { No preference } \\
\text { O preference } \\
\nabla \text { Preference not clear }\end{array}$ \\
\hline \multirow[t]{3}{*}{ Cantonese-English } & Cantonese & 0 & & 0 & \\
\hline & English & - & & 0 & \\
\hline & English & - & & & \\
\hline Cantonese-English-Mandarin & Mandarin & - & & & \\
\hline \multirow[t]{2}{*}{ English-French } & English & - & & & \\
\hline & French & - & & & \\
\hline Korean-Mandarin & Korean & - & & & \\
\hline \multirow[t]{2}{*}{ Mandarin-English } & English & - & & & \\
\hline & Mandarin & - & & & \\
\hline \multirow[t]{2}{*}{ Mandarin-Italian } & Mandarin & - & & & \\
\hline & Italian & - & & & \\
\hline Polish-Dutch & Polish & 0 & & & \\
\hline Russian-Dutch & Russian & 0 & & & \\
\hline \multicolumn{5}{|c|}{$\mathrm{S}=\mathrm{O}$} & $\mathrm{O}>\mathrm{S}$ \\
\hline
\end{tabular}

Figure 9 Studies on heritage language learners. Each symbol represents a relevant experiment in a study.

Figure 10 Studies on multilinguals. Each symbol represents a relevant experiment in a study. 
These studies involve rather heterogeneous groups, including simultaneous bilinguals (Cantonese-English bilinguals in Hong Kong: Yip \& Matthews 2007a; b; and in Australia: Kidd et al. 2015), or sequential bilinguals (Cantonese-English-Mandarin trilinguals in an Englishimmersion school in Hong Kong: Chan et al. 2017; Mandarin-English bilingual children in Italy: Hu \& Guasti 2017; L1-English children learning French in an immersion program in Canada: Scheidnes \& Redmond 2019), or both (Peeters-Podgaevskaja et al. 2020). Others do not specify (Tsoi et al. 2019). Participants also differ in terms of their language dominance within a single study, as well as in terms of the contexts in which they were exposed to their languages (e.g. both languages at home; L1 at home, L2 at school; L2 immersion school).

Nevertheless, the common thread that runs through the studies summarized in this section is that they are interested in children's RC performance in both/all of the languages they speak, as seen in Figure 10, rather than focusing on L1 (in the case of heritage studies) or L2 (in the case of L2 studies), and are also interested in the cross-linguistic influences between the languages. The only exception is Lee \& Lee (2004), which only tested Korean RCs in Korean-Chinese bilinguals. Their study involves Korean immigrants and descendants in a Korean community in China and could be considered a heritage language study, but the authors present it as a bilingual study.

\section{Conclusion}

This paper presents an overview of RC asymmetry research across languages with different typologies and variations in their RC configuration, and across different linguistic groups and diverse methodologies. Based on our review, we conclude by making a few suggestions-both conceptual and practical.

First, all things considered, there is a convergence on a subject advantage; that is, the majority of findings show that SRCs are acquired earlier and are faster to process, easier to produce, preferred in ambiguous cases, and more resistant to language loss than ORCs in many languages. If RCs across languages of different typologies present a subject advantage as a universal tendency, then it is the hierarchical structure of RCs and/or the semantic-pragmatic properties related to the subject argument that result in the SRC advantage, because these are the only explanations that apply cross-linguistically.

That said, there are also some counterexamples, even from English and other well-studied languages, but particularly from languages with prenominal RCs and ergative languages. In fact, none of the existing proposals perfectly account for all the facts, as Pizarro-Guevara (2020) observed. One possibility is that this "universal" phenomenon is a byproduct of the field's initial focus on English and major European languages. At the same time, given the overall trend pointed out in the previous sections, it is possible that there is a true universal that applies across languages, which may not manifest clearly in some languages because of other factors that add additional processing burdens such as headedness, less common animacy configurations, or garden-path effects. For instance, a few studies show that an SRC preference can be obtained in Mandarin when the experimental design removes the influence of main clause ambiguity. Studies on Chamorro and Tagalog suggest that within the same language, postnominal RCs show a clearer subject preference than prenominal RCs.

It is therefore our recommendation that researchers take a multifactorial approach to RC asymmetry when designing an RC study rather than assuming a universal subject advantage, regardless of what the researchers may believe. As we have discussed in Sections 3 and 4, various factors can ameliorate the difficulty associated with the less preferred ORCs. For example, specific animacy configurations or pronominality contrasts between RC arguments make the supposedly more difficult ORCs more accessible. Interactions between typological features have also been shown to play a critical role in modulating RC preferences. Certain language-specific properties allow ORCs to bear features that favor processing expectations. In Mandarin, for example, the canonical word order and the prenominal nature of RCs allow ORCs' constituent order to match processor expectations better than that of SRCs, thereby making ORCs more comparable to SRCs in processing efficiency. In ergative languages, morphological and syntactic preferences for absolutive objects can counteract a subject preference associated with ergative subjects. 
It is also important to draw from multiple types of data to paint a full picture. It is becoming more common for experimental linguists to present both comprehension and production data, which is a desirable trend, but most production data are naturalistic corpus data. While corpora are undoubtedly valuable sources for investigations of the natural use of language, it is also important to elicit production, using an appropriate context that challenges speakers to actively build a sentence, as we suggested in Section 5.5.

In the tremendous amount of RC literature, some avenues of inquiry are quite crowded, but others are relatively neglected. Building a complete picture of the processing and acquisition of RCs will require us to look at different languages, which will open up new approaches to this topic. We invite anyone who works on a language that exhibits interesting properties in terms of word order, headedness, or morphosyntactic alignment to contribute their data. More research is needed on languages with prenominal RCs, as there is a current bias toward languages with postnominal RCs. Languages that allow both prenominal and postnominal RCs are also particularly interesting for exploring the effects of headedness, as we have seen for studies on Chamorro and Tagalog. As we briefly discussed, internally headed RCs are also under-studied. There should also be more studies of RC asymmetry in ergative languages, as they would contribute valuable data for exploring what is special about subjecthood.

Even in well-studied languages, however, there is more to be done. This paper focused on the subject-object comparison, where the research is richest. But much more research testing the psychological validity of the rest of the NPAH (cf. Kim \& O'Grady 2016) is called for if we are to fully understand what such a typological hierarchy can teach us about human language processing. More careful investigation of the incremental processing of RCs using time-sensitive measures and neuroscientific methodologies is also important, as it would lead to a better understanding of the locus of difficulty in RC processing as well as the mechanisms involved in the resolution of long-distance dependencies like RCs.

As for studies on clinical populations, language learners, and heritage speakers, exploring how these populations process RCs gives us opportunities to understand the nature of their language processing better, which may in turn provide useful information for practices in clinical and classroom interventions. Moreover, they offer different grounds for pursuing the mechanisms underlying RC processing and acquisition, reminding us to question what we might take for granted in typical monolingual native speaker populations.

Lastly, this paper limited its focus to RCs because of the wealth of available data. Yet we would add as a final note that RCs form only a subcategory of complex sentences. In fact, many proposals regarding the subject-object asymmetry reviewed in this paper were developed to account for a wide range of phenomena-resource-based effects and structural effects are hypotheses on syntactic movement and long-distance dependencies (e.g. raising, wh-questions), and canonicity effects and distribution-based effects can be used for research on other noncanonical sentence types such as passives. While the historical context surrounding the NPAH has inspired more work on RCs than other phenomena, it is important to use findings from RCs to deepen our general understanding of related phenomena, and to identify the common denominators underlying language typology, learning, and processing.

\section{Abbreviations}

$2=$ second person, $3=$ third person, $\mathrm{A}=$ subject of a transitive verb, $\mathrm{ABS}=$ absolutive, $\mathrm{ACC}$ $=$ accusative, $\mathrm{AF}=$ agent focus, $\mathrm{ASD}=$ autisum spectrum disorder, $\mathrm{AUX}=$ auxiliary, $\mathrm{C}(\mathrm{P})=$ complementizer (phrase), DECL $=$ declarative, $\mathrm{DET}=$ determiner, $\mathrm{ERG}=$ ergative, $\mathrm{ERP}=$ event related potential, FUT $=$ future, GER $=$ gerund, INTR $=$ intransitive, IP $=$ inflectional phrase, $\mathrm{IPFV}=$ imperfective, LAN $=$ left anterior negativity, LOC $=$ locative, $\mathrm{N}(\mathrm{P})=$ noun (phrase), $\mathrm{NOM}=$ nominative, $\mathrm{NPAH}=$ noun phrase accessibility hypothesis, $\mathrm{O}=($ direct $)$ object, $\mathrm{OBL}=$ oblique, $\mathrm{ORC}=$ object relative clause, $\mathrm{PFV}=$ perfective, $\mathrm{PRS}=$ present, $\mathrm{PRTCP}=$ participle, $\mathrm{PST}=$ past, $\mathrm{RC}=$ relative clause, $\mathrm{REL}=$ relativizer, $\mathrm{S}=$ subject, $\mathrm{SG}=$ singular, $\mathrm{SLI}=$ specific language impairment, $\mathrm{SRC}=$ subject relative clause, $\mathrm{TOP}=$ topic, $\mathrm{TR}=$ transitive, $\mathrm{V}(\mathrm{P})=$ verb (phrase), ws = Williams syndrome. Glossing may be modified from the original source to conform to the Leipzig Glossing rules. Roman numerals indicate noun class in Avar. 


\section{Additional Files}

The additional files for this article can be found as follows:

- Supplementary File 1. Data set for Figure 1. Summary of child L1 studies. DOI: https:// doi.org/10.5334/gjgl.1343.s1

- Supplementary File 2. Data set for Figure 2. Summary of adult L1 studies. DOI: https:// doi.org/10.5334/gjgl.1343.s2

- Supplementary File 3. Data set for Figure 3. Summary of L1 studies on ergativeabsolutive languages. DOI: https://doi.org/10.5334/gigl.1343.s3

- Supplementary File 4. Summary of ERP studies. DOI: https://doi.org/10.5334/gigl.1343.s4

- Supplementary File 5. Data set for Figure 7. Summary of clinical studies. DOI: https://doi. org/10.5334/gigl.1343.s5

- Supplementary File 6. Data set for Figure 8. Summary of L2 studies. DOI: https://doi. org/10.5334/gjgl.1343.s6

- Supplementary File 7. Data set for Figure 9. Summary of studies on heritage languages. DOI: https://doi.org/10.5334/gjgl.1343.s7

- Supplementary File 8. Data set for Figure 10. Summary of studies on multilinguals. DOI: https://doi.org/10.5334/gigl.1343.s8

\section{Acknowledgements}

We thank Laurie Durand for her language editing and proofreading services and three anonymous reviewers and the Glossa editorial team for their valuable input.

\section{Competing interests}

The authors have no competing interests to declare.

\section{Authors contributions}

Both Elaine Lau and Nozomi Tanaka contributed to the main conceptual ideas; to the acquisition, analysis, and interpretation of data; and to the drafting and revising of the manuscript. Elaine Lau provided figures.

\section{Author Affiliations}

Elaine Lau (D) orcid.org/0000-0002-5801-6705

Centre for University \& School Partnership, The Chinese University of Hong Kong, Hong Kong

Nozomi Tanaka (D) orcid.org/0000-0003-3910-3659

Department of East Asian Languages and Cultures, Indiana University, IN, US

\section{References}

Abbot-Smith, Kirsten, Franklin Chang, Caroline Rowland, Heather Ferguson \& Julian Pine. 2017. Do two and three year old children use an incremental first-NP-as-agent bias to process active transitive and passive sentences? A permutation analysis. PLoS ONE 12(10). e0186129. DOI: https://doi. org/10.1371/journal.pone.0186129

Adani, Flavia. 2011. Re-thinking the acquisition of relative clauses in Italian: Towards a grammaticallybased account. Journal of Child Language 38(1). 141-165. DOI: https://doi.org/10.1017/ S0305000909990250

Adani, Flavia, Maja Stegenwallner-Schütz, Yair Haendler \& Andrea Zukowski. 2016. Elicited production of relative clauses in German: Evidence from typically developing children and children with specific language impairment. First Language 36(3). 203-227. DOI: https://doi. org/10.1177/0142723716648842

Aissen, Judith. 1999. Markedness and subject choice in optimality theory. Natural Language \& Linguistic Theory 17(4). 673-711. DOI: https://doi.org/10.1023/A:1006335629372

Albirini, Abdulkafi. 2018. The role of age of exposure to English in the development of Arabic as a heritage language in the United States. Language Acquisition 25(2). 178-196. DOI: https://doi.org/10. 1080/10489223.2016.1234620 
Albirini, Abdulkafi \& Elabbas Benmamoun. 2014. Aspects of second-language transfer in the oral production of Egyptian and Palestinian heritage speakers. International Journal of Bilingualism 18(3). 244-273. DOI: https://doi.org/10.1177/1367006912441729

Ambridge, Ben, Evan Kidd, Caroline F. Rowland \& Anna L. Theakston. 2015. The ubiquity of frequency effects in first language acquisition. Journal of Child Language 42(2). 239-273. DOI: https://doi. org/10.1017/S030500091400049X

Ammar, Ahlem \& Patsy M. Lightbown. 2005. Teaching marked linguistic structures: More about the acquisition of relative clauses by Arab learners of English. In Alex Housen \& Michael Pierrard (eds.), Investigations in instructed second language learning, 167-198. Berlin: Mouton de Gruyter.

Arnon, Inbal. 2005. Relative clause acquisition in Hebrew: Toward a processing-oriented account. In Alejna Brugos, Manuella R. Clark-Cotton \& Seungwan Ha (eds.), Proceedings of the 29th Boston University Conference on Language Development (BUCLD), 37-48. Somerville, Massachusetts: Cascadilla Press.

Bar-Shalom, Eva G., Stephen Crain \& Donald Shankweiler. 1993. A comparison of comprehension and production abilities of good and poor readers. Applied Psycholinguistics 14(2). 197-227. DOI: https:// doi. org/10.1017/S0142716400009553

Baudiffier, Vanessa, David Caplan, Daniel Gaonac'h \& David Chesnet. 2011. The effect of noun animacy on the processing of unambiguous sentences: Evidence from French relative clauses. The Quarterly Journal of Experimental Psychology 64(10). 1896-1905. DOI: https://doi.org/10.1080/17470218.2011 .608851

Belletti, Adriana, Naama Friedmann, Dominique Brunato \& Luigi Rizzi. 2012. Does gender make a difference? Comparing the effect of gender on children's comprehension of relative clauses in Hebrew and Italian. Lingua 122. 1053-1069. DOI: https://doi.org/10.1016/j.lingua.2012.02.007

Benţea, Anamaria. 2012. Does "case" matter in the acquisition of relative clauses in Romanian? In Alia Biller, Esther Chung \& Amelia Kimball (eds.), BUCLD 36 Online Proceedings Supplement. http://www. bu.edu/bucld/files/2012/07/Bentea-36.pdf.

Betancort, Moisés, Manuel Carreiras \& Patrick Sturt. 2009. The processing of subject and object relative clauses in Spanish: An eye-tracking study. The Quarterly Journal of Experimental Psychology 62(10). 1915-1929. DOI: https://doi.org/10.1080/17470210902866672

Bever, Thomas G. 1970. The cognitive basis for linguistic structures. In John R. Hayes (ed.), Cognition and development of language, 279-362. New York: Wiley.

Brown, H. Douglas. 1971. Children's comprehension of relativized English sentences. Child Development 42(6). 1923-1936. DOI: https://doi.org/10.2307/1127595

Bulut, Talat, Shih-Kuen Cheng, Kun-Yu Xu, Daisy L. Hung \& Denise H. Wu. 2018. Is there a processing preference for object relative clauses in Chinese? Evidence from ERPs. Frontiers in Psychology 9. 995. DOI: $h$ ttps://doi.org/10.3389/fpsyg.2018.00995

Caplan, David \& Christine Futter. 1986. Assignment of thematic roles to nouns in sentence comprehension by an agrammatic patient. Brain and Language 27(1). 117-134. DOI: https://doi.org/10.1016/0093934X(86)90008-8

Carreiras, Manuel, Jon Andoni Duñabeitia, Marta Vergara, Irene de la Cruz-Pavía \& Itziar Laka. 2010. Subject relative clauses are not universally easier to process: Evidence from Basque. Cognition 115(1). 79-92. DOI: https://doi.org/10.1016/j.cognition.2009.11.012

Chan, Angel, Si Chen, Stephen Matthews \& Virginia Yip. 2017. Comprehension of subject and object relative clauses in a trilingual acquisition context. Frontiers in Psychology 8. 1641. DOI: https://doi. org/10.3389/fpsyg.2017.01641

Chen, Baoguo, Aihua Ning, Hongyan Bi \& Susan Dunlap. 2008. Chinese subject-relative clauses are more difficult to process than the object-relative clauses. Acta Psychologica 129(1). 61-65. DOI: https://doi. org/10.1016/j.actpsy.2008.04.005

Cheng, Tuyuan, Jei-Tun Wu \& Shuanfan Huang. 2018. Use of memory-load interference in processing spoken Chinese relative clauses. Journal of Psycholinguistic Research 47(5). 1035-1055. DOI: https:// doi.org/10.1007/s10936-018-9576-5

Chiu, Bonnie Hui-Chun. 1996. The nature of relative clauses in Chinese-speaking children (NSC Research Report). Taipei: National Taiwan Normal University.

Cho, Sookeun. 1999. The acquisition of relative clauses: Experimental studies on Korean. Honolulu, Hawai ${ }^{i}$ : University of Hawai'i at Mānoa dissertation.

Clemens, Lauren Eby, Jessica Coon, Pedro Mateo Pedro, Adam Milton Morgan, Maria Polinsky, Gabrielle Tandet \& Matthew Wagers. 2015. Ergativity and the complexity of extraction: A view from Mayan. Natural Language \& Linguistic Theory 33(2). 417-467. DOI: https://doi.org/10.1007/s11049-0149260-x

Collins, Chris. 1994. Economy of derivation and the generalized proper binding condition. Linguistic Inquiry 25(1). 45-61.

Comrie, Bernard. 2007. The acquisition of relative clauses in relation to language typology. Studies in Second Language Acquisition 29(2). 301-309. DOI: https://doi.org/10.1017/S0272263107070155 
Croteau, Karen C. 1995. Second language acquisition of relative clause structures by learners of Italian. In Fred R. Eckman, Diane Highland, Peter W. Lee, Jean Mileham \& Rita Rutkowski Weber (eds.), Second language acquisition theory and pedagogy, 115-128. Mahwah, New Jersey: Lawrence Erlbaum.

Cui, Yaqiong. 2013. L2 processing of relative clauses in Mandarin. Arizona Working Papers in SLA \& Teaching 20. 20-39.

de López, Kristine Jensen, Lone Sundahl Olsen \& Vasiliki Chondrogianni. 2014. Annoying Danish relatives: Comprehension and production of relative clauses by Danish children with and without SLI. Journal of Child Language 41(1). 51-83. DOI: https://doi.org/10.1017/S0305000912000517

Diessel, Holger. 2004. The acquisition of complex sentences. Cambridge: Cambridge University Press. DOI: https://doi.org/10.1017/CBO9780511486531

Diessel, Holger. 2007. A construction-based analysis of the acquisition of East Asian relative clauses. Studies in Second Language Acquisition 29(2). 311-20. DOI: https://doi.org/10.1017/ S0272263107070167

Diessel, Holger. 2009. On the role of frequency and similarity in the acquisition of subject and nonsubject relative clauses. In Talmy Givón \& Masayoshi Shibatani (eds.), Syntactic complexity: Diachrony, acquisition, neuro-cognition, evolution, 251-276. Amsterdam: John Benjamins. DOI: https:// doi.org/10.1075/tsl.85.11ont

Diessel, Holger \& Michael Tomasello. 2005. A new look at the acquisition of relative clauses. Language 81(1). 882-906. DOI: https://doi.org/10.1353/lan.2005.0169

Dixon, R. M. W. 1994. Ergativity. Cambridge: Cambridge University Press. DOI: https://doi.org/10.1017/ CB09780511611896

Doughty, Catherine. 1991. Second language instruction does make a difference: Evidence from an empirical study of SL relativization. Studies in Second Language Acquisition 13(4). 431-469. DOI: https://doi.org/10.1017/S0272263100010287

Durrleman, Stephanie, Loyse Hippolyte, Sandrine Zufferey, Katia Iglesias \& Nouchine Hadjikhani. 2015. Complex syntax in autism spectrum disorders: A study of relative clauses. International Journal of Language \& Communication Disorders 50(2). 260-267. DOI: https://doi.org/10.1111/1460-6984.12130

Durrleman, Stephanie, Theodoros Marinis \& Julie Franck. 2016. Syntactic complexity in the comprehension of wh-questions and relative clauses in typical language development and autism. Applied Psycholinguistics 37(6). 1501-1527. DOI: https://doi.org/10.1017/S0142716416000059

Eckman, Fred R., Lawrence Bell \& Diane Nelson. 1988. On the generalization of relative clause instruction in the acquisition of English as a second language. Applied Linguistics 9(1). 1-20. DOI: https://doi. org/10.1093/applin/9.1.1

Foley, Steven. 2020. Case, agreement, and sentence processing in Georgian. Santa Cruz, California: University of California Santa Cruz dissertation.

Forster, Kenneth, Christine Guerrera \& Lisa Jo Elliott. 2009. The maze task: Measuring forced incremental sentence processing time. Behavior Research Methods 41(1). 163-171. DOI: https://doi.org/10.3758/ BRM.41.1.163

Fox, Barbara A. 1987. The noun phrase accessibility hierarchy reinterpreted: Subject primacy or the absolutive hypothesis? Language 63(4). 856-870. DOI: https://doi.org/10.2307/415720

Fox, Barbara A. \& Sandra A. Thompson. 1990. A discourse explanation of the grammar of relative clauses in English conversation. Language 66(2). 297-316. DOI: https://doi.org/10.2307/414888

Frazier, Lyn. 1987. Syntactic processing: Evidence from Dutch. Natural Language \& Linguistic Theory 5. 519-559. DOI: https://doi.org/10.1007/BF00138988

Freeman, Jonathan B. \& Nalini Ambady. 2010. MouseTracker: Software for studying real-time mental processing using a computer mouse-tracking method. Behavior Research Methods 42(1). 226-241. DOI: https://doi.org/10.3758/BRM.42.1.226

Friedmann, Naama, Adriana Belletti \& Luigi Rizzi. 2009. Relativized relatives: Types of intervention in the acquisition of A-bar dependencies. Lingua 119(1). 67-88. DOI: https://doi.org/10.1016/j. lingua.2008.09.002

Friedmann, Naama \& Lewis P. Shapiro. 2003. Agrammatic comprehension of simple active sentences with moved constituents: Hebrew OSV and OVS structures. Journal of Speech, Language, and Hearing Research 46(2). 288-297. DOI: https://doi.org/10.1044/1092-4388(2003/023)

Friedmann, Naama \& Rama Novogrodsky. 2004. The acquisition of relative clause comprehension in Hebrew: A study of SLI and normal development. Journal of Child Language 31(3). 661-681. DOI: https://doi.org/10.1017/S0305000904006269

Gagliardi, Annie, Pedro Mateo Pedro \& Maria Polinsky. 2013. The acquisition of relative clauses in Q'anjob'al Mayan. Paper presented at the 38th Annual Boston University Conference on Language Development (BUCLD), Boston, November 1-3.

Garraffa, Maria \& Nino Grillo. 2008. Canonicity effects as grammatical phenomena. Journal of Neurolinguistics 21(2). 177-197. DOI: https://doi.org/10.1016/j.jneuroling.2007.09.001

Gass, Susan. 1982. From theory to practice. In Mary Hines \& William E. Rutherford (eds.), On TESOL '81: Selected papers from the 15th Annual Conference of Teachers of English to Speakers of Other Languages, 129-139. Washington, DC: TESOL. 
Gennari, Silvia P., Jelena Mirković \& Maryellen C. MacDonald. 2012. Animacy and competition in relative clause production: A cross-linguistic investigation. Cognitive Psychology 65(2). 141-176. DOI: https://doi.org/10.1016/j.cogpsych.2012.03.002

Gennari, Silvia P. \& Maryellen C. MacDonald. 2008. Semantic indeterminacy in object relative clauses. Journal of Memory and Language 58(2). 161-187. DOI: https://doi.org/10.1016/j.jml.2007.07.004

Gibson, Edward. 1998. Linguistic complexity: Locality of syntactic dependencies. Cognition 68(1). 1-76. DOI: https://doi.org/10.1016/S0010-0277(98)00034-1

Gibson, Edward. 2000. The dependency locality theory: A distance-based theory of linguistic complexity. In Alec Marantz, Yasushi Miyashita \& Wayne O’Neil (eds.), Image, language, brain, 95-126. Cambridge, Mssachusetts: MIT Press.

Gibson, Edward \& H.-H. Iris Wu. 2013. Processing Chinese relative clauses in context. Language and Cognitive Processes 28(1-2). 37-41. DOI: https://doi.org/10.1080/01690965.2010.536656

Givón, Thomas. 1983. Topic continuity in discourse: A quantitative cross-language study (Typological Studies in Language 3). Amsterdam: John Benjamins. DOI: https://doi.org/10.1075/tsl.3

Gordon, Peter C., Randall Hendrick \& Marcus Johnson. 2001. Memory interference during language processing. Journal of Experimental Psychology 27(6). 1411-1423. DOI: https://doi.org/10.1037/02787393.27.6.1411

Grodzinsky, Yosef. 1986. Language deficits and the theory of syntax. Brain and Language 27(1). 135-159. DOI: https://doi.org/10.1016/0093-934X(86)90009-X

Grodzinsky, Yosef. 1989. Agrammatic comprehension of relative clauses. Brain and Language 37(3). 480499. DOI: https://doi.org/10.1016/0093-934X(89)90031-X

Guasti, Maria Teresa \& Ur Shlonsky. 1995. The acquisition of French relative clauses reconsidered. Language Acquisition 4(4). 257-276. DOI: https://doi.org/10.1207/s15327817la0404_1

Gundel, Jeanette K., Nancy Hedberg \& Ron Zacharski. 1993. Cognitive status and the form of referring expressions in discourse. Language 69(2). 274-304. DOI: https://doi.org/10.2307/416535

Gutierrez-Mangado, M. Juncal. 2011. Children's comprehension of relative clauses in an ergative language: The case of Basque. Language Acquisition 18(3). 176-201. DOI: https://doi.org/10.1080/104 89223.2011.580674

Gutierrez-Mangado, M. Juncal \& Maria-José Ezeizabarrena. 2012. Asymmetry in child comprehension and production of Basque subject and object relative clauses. In Alia Biller, Esther Chung \& Amelia Kimball (eds.), BUCLD 36 Online Proceedings Supplement. http://www.bu.edu/bucld/files/2012/07/ Gutierrez-Mangado-36.pdf.

Hamburger, Henry \& Stephen Crain. 1982. Relative acquisition. In Stan A. Kuczaj (ed.), Language development, vol. 1: Syntax and semantics, 245-274. Hillsdale, New Jersey: Lawrence Erlbaum.

Hamilton, Robert L. 1994. Is implicational generalization unidirectional and maximal? Evidence from relativization instruction in a second language. Language Learning 44(1). 123-157. DOI: https://doi. org/10.1111/j.1467-1770.1994.tb01451.x

Hansen, Lynne. 1986. Universals in relative clause acquisition: Evidence from child and adult L1 and L2 learners of Hindi-Urdu. Language Learning 36(2). 143-157. DOI: https://doi. org/10.1111/j.1467-1770.1986.tb00376.x

Hatch, Evelyn. 1971. The young child's comprehension of relative clauses. Technical Note 2-71-16. Southwest Regional Laboratory, Los Alamitos, California.

Hawkins, John A. 1999. Processing complexity and filler-gap dependencies across grammars. Language 75(2). 244-285. DOI: https://doi.org/10.2307/417261

Hawkins, John A. 2004. Acquisition of relative clauses in relation to language universals. Oxford: Oxford University Press.

He, Wenguang, Na Xu \& Runqing Ji. 2017. Effects of age and location in Chinese relative clauses processing. Journal of Psycholinguistic Research 46(5). 1067-1086. DOI: https://doi.org/10.1007/ s10936-017-9480-4

Heaton, Raina, Kamil Deen \& William O'Grady. 2016. The status of syntactic ergativity in Kaqchikel. Lingua 170. 35-46. DOI: https://doi.org/10.1016/j.lingua.2015.10.006

Hsiao, Franny \& Edward Gibson. 2003. Processing relative clauses in Chinese. Cognition 90(1). 3-27. DOI: https://doi.org/10.1016/S0010-0277(03)00124-0

Hsu, Chun-Chieh Natalie, Gabriella Hermon \& Andrea Zukowski. 2009. Young children's production of head-final relative clauses: Elicited production data from Chinese children. Journal of East Asian Linguistics 18. 323-360. DOI: https://doi.org/10.1007/s10831-009-9047-y

$\mathrm{Hu}$, Shenai \& Maria Teresa Guasti. 2017. Complexity in the acquisition of relative clauses: Evidence from school-age sequential Mandarin-Italian bilingual children. Journal of International Chinese Education 2. 119-154.

Jäger, Lena, Zhong Chen, Qiang Li, Chien-Jer Charles Lin \& Shravan Vasishth. 2015. The subject-relative advantage in Chinese: Evidence for expectation-based processing. Journal of Memory and Language 79-80. 97-120. DOI: https://doi.org/10.1016/j.jml.2014.10.005 
Jeon, Seon \& Hae-Young Kim. 2007. Development of relativization in Korean as a foreign language. Studies in Second Language Acquisition 29(2). 253-276. DOI: https://doi.org/10.1017/ S0272263107070131

Keenan, Edward L. \& Bernard Comrie. 1977. Noun phrase accessibility and Universal Grammar. Linguistic Inquiry 8(1). 63-99.

Keenan, Edward L. \& Sarah Hawkins. 1987. The psychological validity of the accessibility hierarchy. In Edward L. Keenan (ed.), Universal Grammar: 15 essays, 60-85. London: Croom Helm.

Kidd, Evan, Silke Brandt, Elena Lieven \& Michael Tomasello. 2007. Object relatives made easy: A crosslinguistic comparison of the constraints influencing young children's processing of relative clauses. Language and Cognitive Processes 22(6). 860-897. DOI: https://doi.org/10.1080/01690960601155284

Kidd, Evan, Angel Chan \& Joie Chiu. 2015. Cross-linguistic influence in simultaneous Cantonese-English bilingual children's comprehension of relative clauses. Bilingualism: Language and Cognition 18(3). 438-452. DOI: https://doi.org/10.1017/S1366728914000649

Kim, Chae-Eun \& William O'Grady. 2016. Asymmetries in children's production of relative clauses: Data from English and Korean. Journal of Child Language 43(5). 1038-1071. DOI: https://doi.org/10.1017/ S0305000915000422

Kim, Minjoo. 2004. Event-structure and the internally-headed relative clause construction in Korean and Japanese. Amherst, Massachusetts: University of Massachusetts Amherst dissertation.

Kim, Young-Joo. 1987. The acquisition of relative clauses in English and Korean: Development in spontaneous production. Cambridge, Massachusetts: Harvard University dissertation.

King, Jonathan \& Marcel Adam Just. 1991. Individual differences in syntactic processing: The role of working memory. Journal of Memory and Language 30(5). 580-602. DOI: https://doi. org/10.1016/0749-596X(91)90027-H

King, Jonathan W. \& Marta Kutas. 1995. Who did what and when? Using word- and clause-level ERPs to monitor working memory usage in reading. Journal of Cognitive Neuroscience 7(3). 376-395. DOI: https://doi.org/10.1162/jocn.1995.7.3.376

Kuno, Susumu. 1976. Subject, theme, and the speaker's empathy: A re-examination of relativization phenomena. In Charles N. Li (ed.), Subject and topic, 417-444. New York: Academic Press.

Kwon, Nayoung, Peter C. Gordon, Yoonhyoung Lee, Robert Kluender \& Maria Polinsky. 2010. Cognitive and linguistic factors affecting subject/object asymmetry: An eye-tracking study of prenominal relative clauses in Korean. Language 86(3). 546-582. DOI: https://doi.org/10.1353/lan.2010.0006

Kwon, Nayoung, Robert Kluender, Marta Kutas \& Maria Polinsky. 2013. Subject/object processing asymmetries in Korean relative clauses: Evidence from ERP data. Language 89(3). 537-585. DOI: https://doi.org/10.1353/lan.2013.0044

Labelle, Marie. 1990. Predication, wh-movement, and the development of relative clauses. Language Acquisition 1(4). 95-119. DOI: https://doi.org/10.1207/s15327817la0101_4

Lambrecht, Knud. 1994. Information structure and sentence form: Topic, focus, and the mental representations of discourse referents (Cambridge Studies in Linguistics). Cambridge: Cambridge University Press. DOI: https://doi.org/10.1017/CBO9780511620607

Lau, Elaine. 2016. Acquisition of relative clauses in Cantonese: A multi-factorial analysis. Honolulu, Hawai‘i: University of Hawai'i at Mānoa dissertation.

Lau, Ellen, Michaela Socolof, Nancy Clarke, Rusudan Asatiani \& Maria Polinsky. 2018. A subject relative clause preference in a split-ergative language: ERP evidence from Georgian. College Park, Maryland: University of Maryland manuscript.

Lee-Ellis, Sunyoung. 2011. The elicited production of Korean relative clauses by heritage speakers. Studies in Second Language Acquisition 33(1). 57-89. DOI: https://doi.org/10.1017/S0272263110000537

Lee, Kwee-Ock. 1991. On the first language acquisition of relative clauses in Korean: The universal structure of COMP + . Ithaca, New York: Cornell University dissertation.

Lee, Kwee-Ock \& Sun-Young Lee. 2004. Korean-Chinese bilingual children's comprehension of Korean relative clauses: Rethinking of the structural difference hypothesis. Language Research 40(4). 10591080.

Legum, Stanley. 1975. Strategies in the acquisition of relative clauses. Technical Note 2-75-10. Los Alamitos, California: Southwest Regional Laboratory.

Li, Qiang, Jian Zhang \& Wei Yue. 2010. Chinese relative clauses processing in supportive context removing ambiguity. Studies in Literature and Language 1(4). 12-19.

Lin, Chien-Jer Charles. 2006. Grammar and parsing: A typological investigation of relative-clause processing. Tucson, Arizona: The University of Arizona dissertation.

Lin, Chien-Jer Charles. 2015. Thematic orders and the comprehension of subject-extracted relative clauses in Mandarin Chinese. Frontiers in Psychology 6. 1255. DOI: https://doi.org/10.3389/fpsyg.2015.01255

Lin, Chien-Jer Charles. 2018. Subject prominence and processing dependencies in prenominal relative clauses: The comprehension of possessive relative clauses and adjunct relative clauses in Mandarin Chinese. Language 94(4). 758-797. DOI: https://doi.org/10.1353/lan.2018.0053 
Lin, Chien-Jer Charles \& Thomas G. Bever. 2006. Subject preference in the processing of relative clauses in Chinese. In Donald Baumer, David Montero \& Michael Scanlon (eds.), Proceedings of the 25th West Coast Conference on Formal Linguistics, 254-260. Somerville, Massachusetts: Cascadilla Proceedings Project.

Lin, Chien-Jer Charles \& Thomas G. Bever. 2011. Garden path and the comprehension of head-final relative clauses. In Hiroko Yamashita, Jerome L. Packard \& Yuki Hirose (eds.), Processing and producing head-final structures, 277-297. Dordrecht: Springer. DOI: https://doi.org/10.1007/978-90481-9213-7_13

Lin, Yowyu \& Susan M. Garnsey. 2011. Animacy and the resolution of temporary ambiguity in relative clause comprehension in Mandarin. In Hiroko Yamashita, Jerome L. Packard \& Yuki Hirose (eds.), Processing and producing head-final structures, 277-297. Dordrecht: Springer. DOI: https://doi. org/10.1007/978-90-481-9213-7_12

Longenbaugh, Nicholas \& Maria Polinsky. 2016. The processing of long-distance dependencies in Niuean. In Henrison Hsieh (ed.), AFLA 22: Proceedings of the 22nd Meeting of the Austronesian Formal Linguistics Association, 98-120. Canberra: Asia-Pacific Linguistics. http://hdl.handle.net/1885/101155.

Lukatela, Katarina, Donald Shankweiler \& Stephen Crain. 1995. Syntactic processing in agrammatic aphasia by speakers of a Slavic language. Brain and Language 49(1). 50-76. DOI: https://doi. org/10.1006/brln.1995.1021

Lust, Barbara, Suzanne Flynn \& Claire Foley. 1998. What children know about what they say: Elicited imitation as a research method of assessing children's syntax. In Dana McDaniel, Cecile McKee \& Helen Smith Cairns (eds.), Methods for assessing children's syntax, 55-76. Cambridge, Massachusetts: MIT Press.

Macdonald, Ross, Silke Brandt, Anna Theakston, Elena Lieven \& Ludovica Serratrice. 2020. The role of animacy in children's interpretation of relative clauses in English: Evidence from sentence-picture matching and eye movements. Cognitive Science 44(8). e12874. DOI: https://doi.org/10.1111/ cogs. 12874

MacWhinney, Brian. 1977. Starting points. Language 53. 152-168. DOI: https://doi.org/10.2307/413059

MacWhinney, Brian. 2005. The emergence of grammar and perspective. In Diane Pecher \& Rolf A. Zwaan (eds.), Grounding cognition: The role of perception and action in memory, language and thinking, 198223. Cambridge: Cambridge University Press. DOI: https://doi.org/10.1017/CBO9780511499968.009

MacWhinney, Brian \& Csaba Pléh. 1988. The processing of restrictive relative clauses in Hungarian. Cognition 29(2). 95-141. DOI: https://doi.org/10.1016/0010-0277(88)90034-0

MacWhinney, Brian, Elizabeth Bates \& Reinhold Kliegl. 1984. Cue validity and sentence interpretation in English, German, and Italian. Journal of Verbal Learning and Verbal Behavior 23(2). 127-150. DOI: https://doi.org/10.1016/S0022-5371(84)90093-8

Mak, Willem M., Wietske Vonk \& Herbert Schriefers. 2002. The influence of animacy on relative clause processing. Journal of Memory and Language 47(1). 50-68. DOI: https://doi.org/10.1006/ jmla.2001.2837

Mak, Willem M., Wietske Vonk \& Herbert Schriefers. 2006. Animacy in processing relative clauses: The hikers that rocks crush. Journal of Memory and Language 54(4). 466-490. DOI: https://doi. org/10.1016/j.jml.2006.01.001

Mak, Willem M., Wietske Vonk \& Herbert Schriefers. 2008. Discourse structure and relative clause processing. Memory \& Cognition 36. 170-181. DOI: https://doi.org/10.3758/MC.36.1.170

Mann, Virginia A., Donald Shankweiler \& Suzanne T. Smith. 1984. The association between comprehension of spoken sentences and early reading ability: The role of phonetic representation. Journal of Child Language 11(3). 627-643. DOI: https://doi.org/10.1017/S0305000900005997

Marantz, Alec. 1991. Case and licensing. In Germán F. Westphal, Benjamin Ao \& Hee-Rahk Chae (eds). ESCOL '91: Proceedings of the Eastern States Conference on Linguistics, 234-253. The Department of Linguistics, the Ohio State University.

McKee, Cecile, Dana McDaniel \& Jesse Snedeker. 1998. Relatives children say. Journal of Psycholinguistic Research 27. 573-596. DOI: https://doi.org/10.1023/A:1024901029643

Mecklinger, Axel, Herbert Schriefers, Karsten Steinhauer \& Angela D. Friederici. 1995. Processing relative clauses varying on syntactic and semantic dimensions: An analysis with event-related potentials. Memory \& Cognition 23(4). 477-494. DOI: https://doi.org/10.3758/BF03197249

Montag, Jessica L. \& Maryellen C. MacDonald. 2009. Word order doesn't matter: Relative clause production in English and Japanese. In Niels A. Taatgen \& Hedderik van Rijn (eds.), Proceedings of the Annual Meeting of the Cognitive Science Society 31. 2594-2599. Austin, Texas: Cognitive Science Society.

Muāgututi‘a, Grant. 2018. Recovering ergativity in heritage Samoan. Honolulu, Hawai'i: University of Hawai'i dissertation. http://hdl.handle.net/10125/62507.

Nicol, Janet L., Kenneth I. Forster \& Csaba Veres. 1997. Subject-verb agreement processes in comprehension. Journal of Memory and Language 36(4). 569-587. DOI: https://doi.org/10.1006/

jmla.1996.2497. 
Novogrodsky, Rama \& Naama Friedmann. 2006. The production of relative clauses in syntactic SLI: A window to the nature of the impairment. International Journal of Speech-Language Pathology 8(4). 364-375. DOI: https://doi.org/10.1080/14417040600919496

O’Grady, William. 1997. Syntactic development. Chicago, Illinois: University of Chicago Press.

O'Grady, William. 2011. Relative clauses: Processing and acquisition. In Evan Kidd (ed.), The acquisition of relative clauses: Processing, typology and function, 13-38. Amsterdam: John Benjamins. DOI: https:// doi.org/10.1075/tilar.8.03gra

O'Grady, William, Miseon Lee \& Miho Choo. 2001. The acquisition of relative clauses by heritage and non-heritage learners of Korean as a second language: A comparative study. Journal of Korean Language Education 12. 283-294.

Ono, Hajime, Koichi Otaki, Manami Sato, 'Ana Heti Veikune, Peseti Vea, Yuko Otsuka \& Masatoshi Koizumi. 2020a. Relative clause processing in Tongan: An effect of syntactic ergativity in the object preference. In Ileana Paul (ed.), AFLA 26: Proceedings of the 26th Meeting of the Austronesian Formal Linguistics Association, 192-208. Ontario: University of Western Ontario. https://ir.lib.uwo.ca/afla/ aflaxxvi/meeting/12/.

Ono, Hajime, Koichi Otaki, Manami Sato, 'Ana Heti Veikune, Peseti Vea, Yuko Otsuka \& Masatoshi Koizumi. 2020b. Processing syntactic ergativity in Tongan relative clauses. Paper presented at the 27th Annual Meeting of the Austronesian Formal Linguistics Association (AFLA27), Singapore, August 20-22.

Otaki, Koichi, Manami Sato, Hajime Ono, Noriaki Yusa, Koji Sugisaki, Noriyuki Yusa, Soana Kaitapu, 'Ana Heti Veikune, Peseti Vea, Yuko Otsuka \& Masatoshi Koizumi. 2020. The ergative subject preference in the acquisition of wh-questions in Tongan. In Megan M. Brown \& Alexandra Kohut (ed.), BUCLD 44: Proceedings of the 44th Annual Boston University Conference on Language Development, 465-478. Somerville, Massachusetts: Cascadilla Press. http://www.lingref.com/bucld/44/BUCLD44-37.pdf.

Peeters-Podgaevskaja, Alla V., Bibi E. Janssen \& Anne E., Baker. 2020. The acquisition of relative clauses in Russian and Polish in monolingual and bilingual children. Linguistic Approaches to Bilingualism 10(2). 216-248. DOI: https://doi.org/10.1075/lab.17031.pee

Pérez-Leroux, Ana Teresa. 1995. Resumptives in the acquisition of relative clauses. Language Acquisition 4(1-2). 105-138. DOI: https://doi.org/10.1080/10489223.1995.9671661

Pizarro-Guevara, Jed Sam. 2020. When human universal meets language specific. Santa Cruz, California: University of California Santa Cruz dissertation.

Polinsky, Maria. 2008. Relative clauses in heritage Russian: Fossilization or divergent grammar. In Andrei Antonenko, John F. Bailyn \& Christina Y. Bethin (eds.), Formal approaches to Slavic linguistics: The Stony Brook Meeting 2007, 333-358. Ann Arbor, Michigan: Michigan Slavic Publications.

Polinsky, Maria. 2011. Reanalysis in adult heritage language: New evidence in support of attrition. Studies in Second Language Acquisition 33(2). 305-328. DOI: https://doi.org/10.1017/S027226311000077X

Polinsky, Maria, Carlos Gómez Gallo, Peter Graff \& Ekaterina Kravtchenko. 2012. Subject preference and ergativity. Lingua 122(3). 267-277. DOI: https://doi.org/10.1016/j.lingua.2011.11.004

Pozzan, Lucia, Lila R. Gleitman \& John C. Trueswell. 2016. Semantic ambiguity and syntactic bootstrapping: The case of conjoined-subject intransitive sentences. Language Learning and Development 12(1). 14-41. DOI: https://doi.org/10.1080/15475441.2015.1018420

Qiao, Xiaomei, Liyao Shen \& Kenneth Forster. 2012. Relative clause processing in Mandarin: Evidence from the maze task. Language and Cognitive Processes 27(4). 611-630. DOI: https://doi.org/10.1080/0 1690965.2011.578394

Rahmany, Ramin, Hamideh Marefat \& Evan Kidd. 2011. Persian speaking children's acquisition of relative clauses. European Journal of Developmental Psychology 8(3). 367-388. DOI: https://doi.org/10. 1080/17405629.2010.509056

Rahmany, Ramin, Hamideh Marefat \& Evan Kidd. 2014. Resumptive elements aid comprehension of object relative clauses: Evidence from Persian. Journal of Child Language 41(4). 937-948. DOI: https://doi.org/10.1017/S0305000913000147

Rakhlin, Natalia, Sergey A. Kornilov, Tatiana V. Kornilova \& Elena L. Grigorenko. 2016. Syntactic complexity effects of Russian relative clause sentences in children with and without developmental language disorder. Language Acquisition 23(4). 333-360. DOI: https://doi.org/10.1080/10489223.201 6.1179312

Reali, Florencia \& Morten H. Christiansen. 2007. Processing of relative clauses is made easier by frequency of occurrence. Journal of Memory and Language 57(1). 1-23. DOI: https://doi. org/10.1016/j.jml.2006.08.014

Rizzi, Luigi. 1990. Relativized minimality. Cambridge, Massachusetts: MIT Press.

Roland, Douglas, Frederic Dick \& Jeffrey L. Elman. 2007. Frequency of basic English grammatical structures: A corpus analysis. Journal of Memory and Language 57(3). 348-379. DOI: https://doi. org/10.1016/j.jml.2007.03.002

Schachter, Paul. 1977. Reference-related and role-related properties of subjects. In Peter Cole \& Jerrold Murray Sadock (eds.), Syntax and semantics, vol. 8: Grammatical relations, 279-306. New York: Academic Press. DOI: https://doi.org/10.1163/9789004368866_012 
Scheidnes, Maureen \& Leslie Redmond. 2019. Object relative clause comprehension in L2 children with limited L2 exposure. In Megan M. Brown \& Brady Dailey (eds.), Proceedings of the $43^{\text {rd }}$ Boston University Conference on Language Development (BUCLD), 599-611. Somerville, Massachusetts: Cascadilla Press. http://www.lingref.com/bucld/43/BUCLD43-47.pdf.

Schriefers, Herbert, Angela D. Friederici \& Katja Kühn. 1995. The processing of locally ambiguous relative clauses in German. Journal of Memory and Language 34(4). 499-520. DOI: https://doi.org/10.1006/ jmla.1995.1023

Sekerina, Irina A. 2003. Scrambling and processing: Dependencies, complexity, and constraints. In Simin Karimi (ed.), Word order and scrambling, 301-324. Malden, Massachusetts: Blackwell. DOI: https:// doi.org/10.1002/9780470758403.ch13

Slobin, Dan I. \& Charles A. Welsh. 1973. Elicited imitation as a research tool in developmental psycholinguistics. In Charles A. Ferguson \& Dan I. Slobin (eds.), Studies of child language development, 485-497. New York: Holt, Rinehart and Winston.

Slobin, Dan I. \& Thomas G. Bever. 1982. Children use canonical sentence schemas: A crosslinguistic study of word order and inflections. Cognition 12(3). 229-265. DOI: https://doi.org/10.1016/00100277(82)90033-6

Smith, Suzanne T., Paul Macaruso, Donald Shankweiler \& Stephen Crain. 1989. Syntactic comprehension in young poor readers. Applied Psycholinguistics 10(4). 429-454. DOI: https://doi.org/10.1017/ S0142716400009012

Stern, Michael C., Christen N. Madsen, LeeAnn M. Stover, Cass Lowry \& Gita Martohardjono. 2019. Language history attenuates syntactic prediction in L1 processing. Journal of Cultural Cognitive Science 3(2). 235-255. DOI: https://doi.org/10.1007/s41809-019-00048-y

Swinney, David \& Tracey Love. 1998. The processing of discontinuous dependencies in language and music. Music Perception 16(1). 63-78. DOI: https://doi.org/10.2307/40285778

Tanaka, Nozomi, William O'Grady, Kamil Deen \& Ivan Paul Bondoc. 2019. An asymmetry in the acquisition of relative clauses: Evidence from Tagalog. First Language 39(6). 618-632. DOI: https:// doi.org/10.1177/0142723719859090

Tarallo, Fernando \& John Myhill. 1983. Interference and natural language processing in second language acquisition. Language Learning 33(1). 55-76. DOI: https://doi.org/10.1111/j.1467-1770.1983. tb00986.x

Traxler, Matthew J., Rihana S. Williams, Shelley A. Blozis \& Robin K. Morris. 2005. Working memory, animacy, and verb class in the processing of relative clauses. Journal of Memory and Language 53(2). 204-224. DOI: https://doi.org/10.1016/j.jml.2005.02.010

Traxler, Matthew J., Robin K. Morris \& Rachel E. Seely. 2002. Processing subject and object relative clauses: Evidence from eye movements. Journal of Memory and Language 47(1). 69-90. DOI: https:// doi.org/10.1006/jmla.2001.2836

Tsoi, Elaine Yee Ling, Wenchun Yang, Angel Chan \& Evan Kidd. 2019. Mandarin-English speaking bilingual and Mandarin speaking monolingual children's comprehension of relative clauses. Applied Psycholinguistics 40(4). 933-964. DOI: https://doi.org/10.1017/S0142716419000079

Ueno, Mieko \& Susan M. Garnsey. 2008. An ERP study of the processing of subject and object relative clauses in Japanese. Language and Cognitive Processes 23(5). 646-688. DOI: https://doi. org/10.1080/01690960701653501

Van Valin, Robert D., Jr. \& David P. Wilkins. 1996. The case for "effector": Case roles, agents, and agency revisited. In Masayoshi Shibatani \& Sandra A. Thompson (eds.), Grammatical constructions: Their form and meaning, 289-322. Oxford: Oxford University Press, Clarendon Press.

Varlokosta, Spyridoula \& Sharon Armon-Lotem. 1998. Resumptives and wh-movement in the acquisition of relative clauses in Modern Greek and Hebrew. In Annabel Greenhill, Mary Hughes, Heather Littlefield \& Hugh Walsh (eds.), Proceedings of the 22nd Annual Boston University Conference on Language Development (BUCLD), 737-746. Somerville, Massachusetts: Cascadilla Press.

Vasishth, Shravan \& Richard L. Lewis. 2006. Argument-head distance and processing complexity: Explaining both locality and antilocality effects. Language 82(4). 767-794. DOI: https://doi. org/10.1353/lan.2006.0236

Vasishth, Shravan, Zhong Chen, Qiang Li \& Gueilan Guo. 2013. Processing Chinese relative clauses: Evidence for the subject-relative advantage. PLoS ONE 8(10). e77006. DOI: https://doi.org/10.1371/ journal.pone.0077006

Wagers, Matthew W., Manuel F. Borja \& Sandra Chung. 2018. Grammatical licensing and relative clause parsing in a flexible word-order language. Cognition 178. 207-221. DOI: https://doi.org/10.1016/j. cognition.2018.05.006

Wanner, Eric \& Michael Maratsos. 1978. An ATN approach to comprehension. In Joan Bresnan, George Armitage Miller \& Morris Halle (eds.), Linguistic theory and psychological reality, 119-161. Cambridge, Massachusetts: MIT Press.

Warren, Tessa \& Edward Gibson. 2002. The influence of referential processing on sentence complexity. Cognition 85(1). 79-112. DOI: https://doi.org/10.1016/S0010-0277(02)00087-2 
Wu, Zhaohong \& Alan Juffs. 2016. What kind of priming is most effective in the processing of relative clauses in context? In Patrick Farrell (ed.), Proceedings of the Linguistic Society of America Annual Meeting (LSA) 1(37). 1-15. Washington, DC: Linguistic Society of America. DOI: https://doi. org/10.3765/plsa.v1i0.3728

Xu, Kunyu, Jeng-Ren Duann, Diasy L. Hung \& Denise H. Wu. 2019. Preference for object relative clauses in Chinese sentence comprehension: Evidence from online self-paced reading time. Frontiers in Psychology 10. 2210. DOI: https://doi.org/10.3389/fpsyg.2019.02210

Yabuki-Soh, Noriko. 2007. Teaching relative clauses in Japanese: Exploring alternative types of instruction and the projection effect. Studies in Second Language Acquisition 29(2). 219-252. DOI: https://doi.org/10.1017/S027226310707012X

Yip, Virginia \& Stephen Matthews. 2007a. The bilingual child: Early development and language contact. Cambridge: Cambridge University Press. DOI: https://doi.org/10.1017/CBO9780511620744

Yip, Virginia \& Stephen Matthews. 2007b. Relative clauses in Cantonese-English bilingual children: Typological challenges and processing motivations. Studies in Second Language Acquisition 29(2). 277-300. DOI: https://doi.org/10.1017/S0272263107070143

Zukowski, Andrea. 2009. Elicited production of relative clauses in children with Williams syndrome. Language and Cognitive Processes 24(1). 1-43. DOI: https://doi.org/10.1080/01690960801966118
TO CITE THIS ARTICLE: Lau, Elaine and Nozomi Tanaka. 2021. The subject advantage in relative clauses: A review. Glossa: a journal of general linguistics 6(1): 34. 1-34. DOI: https://doi. org/10.5334/gjgl.1343

Submitted: 11 June 2020 Accepted: 26 January 2021 Published: 05 April 2021

\section{COPYRIGHT:}

(c) 2021 The Author(s). This is an open-access article distributed under the terms of the Creative Commons Attribution 4.0 International License (CC-BY 4.0), which permits unrestricted use, distribution, and reproduction in any medium, provided the original author and source are credited. See http:// creativecommons.org/ licenses/by/4.0/.

Glossa: a journal of general linguistics is a peer-reviewed open access journal published by Ubiquity Press. 